University of Wollongong

Research Online

Faculty of Business - Papers (Archive)

Faculty of Business and Law

$1-1-2013$

Fundamentals or managerial discretion? The relationship between accrual variability and future stock return volatility

Yaowen Shan

University of Technology Sydney

Stephen Taylor

University of Technology Sydney

Terry S. Walter

University of Technology Sydney, twalter@uow.edu.au

Follow this and additional works at: https://ro.uow.edu.au/buspapers

Part of the Business Commons

Research Online is the open access institutional repository for the University of Wollongong. For further information contact the UOW Library: research-pubs@uow.edu.au 


\title{
Fundamentals or managerial discretion? The relationship between accrual variability and future stock return volatility
}

\author{
Abstract \\ This study extends the theoretical framework of Callen and Segal (2004) and Vuolteenaho (2002) to \\ investigate the association between accrual variability and firm-level stock return volatility. The empirical \\ evidence supports our prediction that increased uncertainty in current-period accounting accruals is \\ associated with significantly higher volatility of future stock returns, and the results are valid for measures \\ of both systematic and idiosyncratic volatility. When accrual variability is decomposed into fundamental \\ and discretionary portions, we find that the positive relationship between accrual variability and future \\ stock return volatility is dominated by the fundamental component of accrual variability. Overall, our \\ results suggest that uncertainty reflected in accrual information is subsequently reflected in the \\ fluctuation of future stock returns, and that the predictive content in accruals primarily reflects firms' \\ fundamental uncertainty, rather than any effects of managerial choices and interventions in the \\ accounting process.

\section{Disciplines} \\ Business

\section{Publication Details} \\ Shan, Y., Taylor, S. \& Walter, T. (2013). Fundamentals or managerial discretion? The relationship between \\ accrual variability and future stock return volatility. Abacus: a journal of accounting, finance and business \\ studies, 49 (4), 441-475.
}




\title{
Fundamentals or Managerial Discretion? The Relationship
}

\section{between Accrual Variability and Future Stock Return}

\begin{abstract}
Volatility
This paper extends the theoretical framework of Callen and Segal (2004) and Vuolteenaho (2002) to investigate the association between accrual variability and firm-level stock return volatility. The empirical evidence supports our prediction that increased uncertainty in accounting accruals is associated with significantly higher volatility of future stock returns, and the results are valid for measures of both systematic and idiosyncratic volatility. When accrual variability is decomposed into fundamental and discretionary portions, we find that the positive relationship between accrual variability and future stock return volatility is dominated by the fundamental component of accrual variability. Overall, our results suggest that uncertainty reflected in accrual information is subsequently reflected in the fluctuation of future stock returns, and that the predictive content in accruals primarily reflects firms' fundamental uncertainty, rather than any effect of managerial choices and interventions in the accounting process.
\end{abstract}

Key words: Accruals variability; Stock return volatility; Systematic and idiosyncratic risk; Fundamental and discretionary components; Managerial discretion.

\footnotetext{
* Corresponding author

YAOWEN SHAN (yaowen.shan@uts.edu.au) is a Lecturer in Accounting;

STEPHEN TAYLOR (stephen.taylor@uts.edu.au) is a Professor of Accounting and;

TERRY WALTER (terry.walter@uts.edu.au) is a Professor of Finance, all at the UTS Business School, University of Technology, Sydney.
}

The authors acknowledge the helpful suggestions of Eli Bartov, Philip Brown, Dan Dhaliwal, Peter Easton, Neal Fargher, Jere Francis, John Lyon, Tom Smith, Nasser Spear, Joseph Weber and Sarah Zechman, attendees at the University of Technology, Sydney Summer Research School and the American Accounting Association Annual Meeting, as well as workshop participants at the Australian National University, University of Melbourne, University of Auckland, University of Western Australia and Victoria University, Wellington. The authors acknowledge research support from the Accounting and Audit Quality program of the Capital Markets Co-operative Research Centre, a research centre established by the Federal Government of Australia. 


\section{INTRODUCTION}

This paper provides a theoretical basis for predicting how the volatility of accounting accruals (i.e., the uncertainty inherent in accruals) is reflected in subsequent stock return volatility. Focusing on the variance of accruals (rather than the variance of an accruals model residuals as in Dechow and Dichev (2002)), our paper extends the Callen-Segal (2004) and Vuolteenaho (2002) models to establish a theoretical framework linking accrual variability and the ex post variance of stock returns. Our modelling demonstrates that the conditional variance of accounting accruals is part of the conditional variance of stock returns. Our main hypothesis is therefore rather intuitive. Given the assumption that stock prices reflect the implications of current earnings for future earnings, future stock returns are expected to be more volatile if accounting accruals are more volatile. We then subsequently provide empirical confirmation of this hypothesis.

Unlike most existing studies that concentrate on the mean properties of accounting accruals, we focus on accrual variability. ${ }^{1}$ Due to the mean reverting nature of accruals, a higher level of accruals must be accompanied by higher accrual variability. Accrual variability (as distinct from the mean level of accruals) is of interest for a number of reasons. First, a variability-based measure of accruals can be an appropriate measure of earnings risk. Yee (2006) suggests that earnings quality risk can be viewed as a 'second moment effect arising from accruals noise', while Dechow and Dichev (2002) interpret better accrual quality as the extent to which accruals map into previous, current and future cash flows. Second, accrual variability has an economic meaning quite distinct from the mean properties of accruals. Larger accrual variability would allow a relatively higher level of earnings intervention (in either direction) to be undertaken without being detected as earnings management. Hence, measures of accrual variability are also useful to address issues like earnings quality, the nature of the information environment, and the effect of accounting standard 
setting.

We recognize that accrual volatility can arise from two distinct factors. First, there is fundamental uncertainty due to economic shocks from the firm's business model, organizational structure and operating environment. This is analogous to what Francis et al. (2005) label as the innate component of accounting accruals, or ultimately, innate accounting quality. The second component of accrual volatility is the discretionary component, which reflects managerial choices and interventions in the accounting process. $^{2}$ We therefore extend our analysis of the association between accrual variability and stock return volatility to consider the separate effects of fundamental uncertainty and managerial discretion.

Our theoretical insight stems from two accounting versions of the Campbell-Shiller model (Campbell and Shiller 1988a, 1988b; Vuolteenaho 2002; Callen and Segal 2004). Callen and Segal (2004) develop their model by incorporating the Feltham-Ohlson $(1995,1996)$ clean surplus relation in the Campbell-Shiller model, and include accounting accruals (defined as the change in the firm's operating assets) in a variance decomposition framework to examine the relative impact of accruals news and expected-return news on unexpected changes in current returns. ${ }^{3}$ Vuolteenaho (2002), on the other hand, extends the log-linear dynamic dividend growth model of Campbell and Shiller to the firm level by substituting accounting earnings for dividends via the accounting clean surplus identity, and finds that earnings news dominates expected-return news in explaining equity returns at the firm level. ${ }^{4}$ We extend the Callen and Segal (2004) and Vuolteenaho (2002) models and establish a theoretical link between accrual variability and future stock return volatility.

We conduct our empirical analysis at the firm level, because firm-level stock return volatility is important for managers and shareholders. ${ }^{5}$ Consistent with many prior studies, we utilize regression analysis (Pástor and Veronesi 2003; Wei and Zhang 
2006; Ferreira and Laux 2007; Irvine and Pontiff 2009; Brandt et al. 2010). ${ }^{6}$ Using data from the merged Compustat and CRSP database from 1974 to 2009, we show that the volatility of accounting accruals is positively associated with the variance of future stock returns. A one standard deviation increase in the log of accrual variability results in an increase in the log of stock return volatility exceeding $30 \%$. This positive relationship remains significant even after accounting for other known determinants of stock return volatility.

We further decompose accrual variability into fundamental and discretionary components and examine whether these two components have distinct effects on stock return volatility. Guay et al. (1996), Subramanyam (1996) and Francis et al. (2005) suggest that discretionary accrual choices are likely to reflect both managerial opportunism (which exacerbates information uncertainty) and performance measurement (which reduces information uncertainty). As a result, these conflicting influences will yield an average effect for the discretionary component that is likely to be less than the effects for the fundamental component. On the other hand, Yee (2006) and Chen et al. (2008) extend the analysis of Francis et al. (2005) and demonstrate that the effect of discretionary accrual choices on market prices and the cost of capital depends critically on the level of fundamental uncertainty. Kim and Qi (2010) and Liu and Wysocki (2007) also argue that the documented relationship between accrual quality and the cost of capital is primarily driven by fundamental risks that are less subject to managerial manipulation.

Our results indicate that the positive relationship between accrual variability and future stock return volatility is mostly sourced from the fundamental portion. In particular, a one standard deviation increase in the log of the fundamental component of accrual variability results in a more than $40 \%$ increase in the log of stock return volatility, while the effect of the discretionary component is substantially lower and economically insignificant (less than 7\%). These findings are consistent with Kim and Qi (2010) and Liu and Wysocki (2007) and suggest that the uncertainty of accrual 
information contributes to the fluctuation of future stock returns and that its predictive content is a reflection of firms' fundamental uncertainty rather than managerial choices and interventions in the accounting process.

We also separately consider whether accrual variability is associated with differences in systematic or idiosyncratic risk. It is not surprising that the relationship should hold for idiosyncratic volatility, as this accounts for most of total stock return volatility. While our model does not offer any guidance on systematic volatility, results similar to those for idiosyncratic volatility would be expected if accrual information has substantial undiversified variation and contains market-level information. This is supported by recent studies examining the predictive content of aggregate accruals (Hirshleifer et al. 2009) and aggregate accrual components (Kang et al. 2010; Guo and Jiang 2011). ${ }^{7}$ Using the CAPM and the Fama-French three factor model (Fama and French 1993, 1996) as benchmarks to decompose total volatility into systematic and idiosyncratic components, we find that the significant relationship between the uncertainty of accruals and stock return volatility occurs for both components of volatility.

To avoid spurious correlations, we control for a large set of volatility covariates. Our results are robust to different measures of stock return volatility, different measures of accruals, alternative decomposition approaches for accrual variability as well as observations drawn from different U.S. stock exchanges. Using different econometric frameworks including Fama-MacBeth (1973) regressions, fixed and random effect regressions, and regressions using two-way clustered standard errors (Petersen 2009), we still find a significant relationship between accrual variability and stock return volatility. The results continue to hold even after accounting for a possible new listing bias in the 1980s (Fama and French 2004; Wei and Zhang 2006), so-called technology bubbles (Chan et al. 2001; Schwert 2002), loss reporting (Givoly and Hayn 2000) and the inclusion of lagged stock return volatility. 
Our theoretical and empirical results make a number of contributions. First, they extend our understanding on how uncertainty reflected in accruals information relates to future stock prices. Recent research yields inconclusive evidence on the association between stock prices and the uncertainty (or quality) of accruals information, as proxied by the variance of different accruals measures. Francis et al. (2005) document that lower quality accrual information (AQ) is associated with larger costs of equity, but Core et al. (2008) find no evidence that AQ is a priced risk factor. Kim and Qi (2010) and Ogneva (2010) further argue that high AQ firms do outperform low AQ firms after removing low-priced stocks or controlling for cash flow shocks respectively. ${ }^{8}$ Our paper focuses explicitly on the uncertainty of accruals information and provides insights on the predictive content of accrual information by examining its link to future stock price fluctuations.

Second, we utilize the Francis et al. (2005) decomposition methodology to investigate the relative importance of the fundamental and discretionary components of accrual variability on future stock return volatility. ${ }^{9}$ Francis et al. (2005) find that both fundamental and discretionary factors affect the cost of capital, although the impact of the fundamental part is larger. Yee (2006), however, provides an analytical model in which risk is decomposed into fundamental risk and earnings quality risk, and shows that earnings quality risk magnifies fundamental risk but has no effect on the cost of capital in the absence of fundamental risk. ${ }^{10}$ Kim and Qi (2010) find the pricing effect of accrual quality is prominent in the fundamental part. ${ }^{11}$ We focus on the relationship between accrual variability and future stock return volatility and present results consistent with Kim and Qi (2010) and Liu and Wysocki (2007) that the association is mostly sourced from the fundamental component of accrual information.

Third, our study addresses the broader question as to what explains cross-sectional differences in stock return volatility. While a limited amount of evidence relates stock return volatility with financial disclosure (Bushee and Noe 2000), firm age (Pástor 
and Veronesi 2003), accounting earnings (Wei and Zhang 2006) and governance mechanisms (Ferreira and Laux 2007), our tests complement existing evidence by focusing on the uncertainty of accruals information in relation to future firm-level stock return volatility. We do so by extending existing studies based on the Campbell-Shiller loglinear valuation formula (Vuolteenaho 2002; Callen and Segal 2004) and examining the relative importance of the fundamental and discretionary components of accrual variability in relation to both systematic and idiosyncratic stock return volatility in the future.

Finally, our study also contributes to the relatively scant literature on the role of accounting-based risk measures. The seminal work by Beaver et al. (1970) shows that earnings-based risk measures are positively associated with beta. More recently, Baginski and Wahlen (2003) find that earnings volatility and beta help explain risk implicit in stock prices. Nekrasov and Shroff (2008) incorporate systematic earnings risk directly in the estimation of firm value and cost of equity. Penman (2006) argues in favour of earnings-based risk measures and calls for research to examine fundamental sources of risk by looking at earnings components. Our paper examines an accrual-based risk measure, namely accrual variability, and examines the link between risk in accrual components (innate versus discretionary) and future return volatility.

The rest of this paper is organized as follows. The next section establishes the theoretical relationship between accrual variability and stock return volatility. We then describe the sample construction and the decomposition of accrual variability, as well as discussing descriptive statistics and correlation analysis. The following section outlines the results of the cross-sectional regression linking accrual variability and stock return volatility. The decompositions of accrual variability and total volatility are also examined. Further robustness analysis is then considered and the last section concludes the paper. 


\section{HYPOTHESIS DEVELOPMENT}

At the most fundamental level, stock prices are the sum of expected future payoffs adjusted by the appropriate discount rates. Campbell and Shiller (1988a, 1988b) use a loglinear approximation to represent the relationship between prices, dividends and returns, which provides an accounting framework where high prices must be associated with high expected future dividends, low expected future return, or some combination of the two. Campbell (1991) and Campbell and Ammer (1993) find that expected-return news dominates dividend news in driving equity returns at the aggregate market-wide level.

Our first approach is based on extending the Callen-Segal (2004) model. Callen and Segal (2004) use the definition of the operating assets to market value ratio and the Feltham-Ohlson clean surplus relations and derive an accounting-based valuation model. This allows accruals to be included in a model similar in structure to the Campbell-Shiller model. In particular, Callen and Segal (2004) decompose unexpected stock returns into an expected-return news component and an accrual news component as follows:

$$
r_{i t}-E_{t-1} r_{i t}=\Delta E_{t} \sum_{j=0}^{\infty} \rho^{j}\left(A C C_{i, t+j}-f_{t+j}\right)-\Delta E_{t} \sum_{j=0}^{\infty} \rho^{j} r_{i, t+j}
$$

where $r_{i t}$ is the return on stock $i$ in period $(t-1, t), A C C_{i, t+j}$ is the accrual in the Feltham-Ohlson fashion in period $(t+j-1, t+j)$ defined as the growth in net operating assets, $f_{t+j}$ is the risk-free rate for period $(t+j-1, t+j), \rho$ is a constant slightly less than one, and $\kappa_{i t}$ is an approximation error. In the expression, $E_{t-1}$ is the expectation conditional on the information available at $t-1$ and $\Delta E_{t}=E_{t}-E_{t-1}$ (i.e., the change in expectation from $t$-1 to $t$ ). Callen and Segal (2004) find that the accruals news significantly dominants the expected-return news at the firm level, and the variance of accrual news is more than twice that of expected-return news. Following Wei and Zhang (2006), we take a first approximation of the unexpected-return variance and 
focus our attention on the conditional variance of the accrual news. The relationship can be derived from equation (1),

$$
\operatorname{Var}_{t-1}\left(r_{i t}\right)=\operatorname{Var}_{t-1}\left[\Delta E_{t} \sum_{j=0}^{\infty} \rho^{j} A C C_{i, t+j}\right]+\xi_{i, t-1}
$$

where $\xi_{i, t-1}$ encompasses the conditional variances of the expected-return news and the conditional covariance between the accrual news and expected-return news.

Suppose $A C C_{t}$ satisfies the following autoregressive process with conditional heteroscedastic error terms:

$$
A C C_{t+1}=a+\lambda * A C C_{t}+e_{t+1}
$$

where $\lambda$ is a fixed persistence parameter, $a$ is the intercept, and $e_{t}$ is the independent, unpredictable, mean zero disturbance term. If $A C C_{t}$ follows process (3), it is easy to derive (see Appendix A for details),

$$
\operatorname{Var}_{t-1}\left(\Delta E_{t} \sum_{j=0}^{\infty} \rho^{j} A C C_{t+j}\right)=\frac{1}{(1-\rho \lambda)^{2}} \operatorname{Var}_{t-1}\left(e_{t}\right)
$$

And thus

$$
\operatorname{Var}_{t-1}\left(r_{t}\right)=\frac{1}{(1-\rho \lambda)^{2}} \operatorname{Var}_{t-1}\left(e_{t}\right)+\xi_{t-1}
$$

Equation (5) suggests that the conditional variance of accounting accruals news $\left(\operatorname{Var}_{t-1}\left(e_{t}\right)\right)$ is part of the conditional variance of stock returns.

Our second approach is based on an extension of the Vuolteenaho (2002) model. Vuolteenaho (2002) uses the definition of the book to market ratio and the accounting clean surplus relation (Ohlson 1995) to transform dividends in the Campbell-Shiller model, and sets up a new link between unexpected stock returns and changes in future discount rates, and expected future ROEs as follows;

$$
r_{i t}-E_{t-1} r_{i t}=\Delta E_{t} \sum_{j=0}^{\infty} \rho^{j}\left(R O E_{i, t+j}-f_{t+j}\right)-\Delta E_{t} \sum_{j=0}^{\infty} \rho^{j} r_{i, t+j}+\kappa_{i t}
$$

where $r_{i t}$ is the return on stock $i$ in period $(t-1, t), R O E_{i, t+j}$ is the return-on-equity in 
period $(t+j-1, t+j), f_{t+j}$ is the risk-free rate for period $(t+j-1, t+j), \rho$ is a constant slightly less than one, and $\kappa_{i t}$ is an approximation error. Vuolteenaho (2002) finds that cash-flow news, measured by return-on-equity news, is dominant in the right hand side of equation (6) at the firm level, and the variance of cash-flow news is more than twice that of expected-return news. Taking a first approximation of the unexpected-return variance, we derive the conditional variance of the cash flow news from equation (6),

$$
\operatorname{Var}_{t-1}\left(r_{i t}\right)=\operatorname{Var}_{t-1}\left[\Delta E_{t} \sum_{j=0}^{\infty} \rho^{j} R O E_{i, t+j}\right]+\eta_{i, t-1}
$$

where $\eta_{i, t-1}$ encompasses the conditional variances of the expected-return news and the conditional covariance between the cash flow news and expected-return news.

We then split the net income measure in Vuolteenaho (2002) into an accruals component $\left(A C C E_{t}\right)$ and a cash flow component $\left(C F E_{t}\right)$, where $A C C E_{t}$ is equal to total accruals scaled by lagged book value of equity, and $C F O_{t}$ is equal to cash flow from operations scaled by lagged book value of equity. Suppose both $A C C E_{t}$ and $C F E_{t}$ satisfy the following autoregressive process with conditional heteroscedastic error terms:

$$
\begin{gathered}
A C C E_{t+1}=a+\beta A C C E_{t}+\theta C F E_{t+1}+u_{t+1},(8 \mathrm{a}) \\
C F E_{t+1}=b+\gamma C F E_{t}+v_{t+1},(8 \mathrm{~b})
\end{gathered}
$$

where $\beta, \theta$ and $\gamma$ are fixed persistence parameters that are non-negative and less than one, $a$ and $b$ are the intercepts, $u_{t}$ and $v_{t}$ are the independent, unpredictable, mean zero disturbance terms. Unlike previous studies utilizing a simple AR(1) process (e.g. Freeman et al. 1982; Cheng 2005), we include the contemporaneous relationship between accruals and operating cash flow in equation (8) as suggested by Dechow and Dichev (2002) and Wysocki (2009).

If $A C C E_{t}$ and $C F E_{t}$ follow process (8), it is easy to derive (see Appendix B for details), 


$$
\operatorname{Var}_{t-1}\left(\Delta E_{t} \sum_{j=0}^{\infty} \rho^{j} R O E_{t+j}\right)=\frac{1}{(1-\rho \beta)^{2}} \operatorname{Var}_{t-1}\left(u_{t}\right)+\frac{(\theta+1-\rho \beta)^{2}}{(1-\rho \beta)^{2}(1-\rho \gamma)^{2}} \operatorname{Var}_{t-1}\left(v_{t}\right)
$$

And thus

$$
\operatorname{Var}_{t-1}\left(r_{t}\right)=\frac{1}{(1-\rho \beta)^{2}} \operatorname{Var}_{t-1}\left(u_{t}\right)+\psi_{t-1}
$$

where $\psi_{i, t-1}$ encompasses the conditional variances of cash flow news and $\eta i, t-1$. Although the definition of accounting accruals used in the Vuolteenaho model differs from the Callen-Segal model, the second approach also suggests that the conditional variance of accounting accrual news $\left(\operatorname{Var}_{t-1}\left(u_{t}\right)\right)$ is part of the conditional variance of stock returns. However, the second approach differs from the first one in that it suggests the conditional variance of cash flow news is also an important part of the conditional variance of stock returns (see equation (9)). In the empirical analysis below, we adopt a non-parametric approach in constructing the conditional variance of accruals, without modelling the stochastic process for accruals. In particular, we use the realized volatility of accounting accruals available at time $t-1$ as the non-parametric estimator, but the main results remain identical when using the residuals estimated from equation (3) or (8) as the inputs for accruals variability (although such estimation requires a substantial time series of observations, thereby introducing sample selection bias). ${ }^{12}$ The main hypothesis is stated as follows:

H1: The future volatility of a firm's stock returns increases with the variation of accounting accruals.

The intuition of the main hypothesis is as follows. Given the assumption that stock prices reflect the implications of current earnings for future earnings, then if current accounting accruals are more variable, reflecting increasing uncertainty about future payoffs, future stock returns will also be more volatile. ${ }^{13}$

The theoretical models discussed above establish the relationships between accrual variability and future stock return volatility, but do not distinguish the effects of different sources of accruals uncertainty. However, the accruals variability we 
consider is jointly determined by fundamental (innate) factors, such as firms' business models and operating environments, as well as by management's (discretionary) reporting and implementation decisions. Thus, we further decompose the conditional variance of accruals news into its fundamental and discretionary components, and investigate their relationship with future stock return volatility.

Prior research suggests that variability of the fundamental and discretionary accrual components may have a differential impact on future stock return volatility. Guay et al. (1996) and Subramanyam (1996) provide a framework in which discretionary accruals and non-discretionary accruals will have distinct effects on stock prices. Briefly, this body of work suggests that discretionary accrual choices are likely to reflect both managerial opportunism (which exacerbates information uncertainty) and performance measurement (which reduces information uncertainty). These conflicting effects will yield an average effect for discretionary accruals that is likely to be less than the effects for non-discretionary accruals.

Francis et al. (2005) find that the fundamental portion of accrual quality has a larger impact on the cost of capital than does the discretionary portion, yet both have a significant effect on the cost of capital. However, in linking earnings quality to the equity risk premium, Yee (2006) demonstrates that in the absence of fundamental risk, earnings quality risk has no effect on the cost of capital, and that increasing fundamental risk serves to magnify the effect of earnings quality risk on the cost of capital. Chen et al. (2008) extend the empirical analysis of Francis et al. (2005), and report empirical results consistent with Yee's (2006) predictions that the relationship between earnings quality and the cost of capital depends critically on the level of fundamental uncertainty.

Kim and Qi (2010) suggest that accrual quality contributes to the cost of capital and its pricing effect is prominent in the innate component of accrual quality but not in the discretionary component. Liu and Wysocki (2007) also find that the accrual quality 
measure displays inconsistent associations with cost of capital when including firms' fundamental risk, operating volatility, as a control. ${ }^{14}$ Thus, to the extent that our disaggregation successfully separates the underlying fundamental and discretionary portion of accruals variability, we would expect the relationship between future stock return volatility and the discretionary portion of accruals to be weaker than for the fundamental portion. Our second hypothesis is stated as follows:

$\mathrm{H}$ 2: $\quad$ The positive relationship with future stock return volatility is stronger for the fundamental component of accruals uncertainty than for the discretionary component.

If the above hypothesis holds, it is also of interest to examine whether the information contained in accruals (mainly) determines the cross-sectional differences in systematic or idiosyncratic volatility. Given that the finance literature suggests that idiosyncratic volatility accounts for most of total stock return volatility (Campbell et al. 2001; Wei and Zhang 2006), we would expect that the above hypothesis holds for idiosyncratic volatility.

While our model does not offer any guidance on systematic volatility, results similar to those for idiosyncratic volatility would be expected if accrual information has substantial undiversified variation and contains market-level information. Hirshleifer et al. (2009) document that aggregate accruals positively predict aggregate stock returns and innovations in aggregate accruals are negatively correlated with contemporaneous market returns. They conclude that 'these findings suggest that innovations in accruals and cash flows contain information about changes in discount rates, or that firms manage earnings in response to marketwide undervaluation' (Hirshleifer et al. 2009, p. 389).

Further support is provided by Kang et al. (2010) and Guo and Jiang (2011). In particular, Kang et al. (2010) find that the results in Hirshleifer et al. (2009) are 
driven by discretionary accruals but not normal accruals, indicating managers time aggregate equity markets to report earnings. Guo and Jiang (2011), on the other hand, present evidence in favour of the risk-based explanation and suggest that aggregate accruals, as a proxy for the conditional equity premium, forecast changes in aggregate economic activity. Therefore, we would expect that accruals news generates aggregate stock return variation. Our third and fourth hypotheses are stated as follows:

H3: Both future systematic and idiosyncratic volatility of a firm's stock return increases with the variation of accounting accruals.

H4: The positive relationship with future systematic and idiosyncratic stock return volatility is stronger for the fundamental component of accruals uncertainty than for the discretionary component.

\section{DATA AND DESCRIPTIVE STATISTICS}

\section{The Sample}

The data for this study are obtained from the intersection of annual Compustat, and daily and monthly Centre for Research in Security Prices (CRSP) databases commencing 1974 through to 2009. The data sample contains all active and inactive firms listed on the New York Stock Exchange (NYSE), the NASDAQ and the American Stock Exchange (AMEX). ${ }^{15}$ Only firms with positive values for one lag of book value of equity, net operating assets, operating assets, operating liabilities, financial liabilities and positive total assets are included in the sample. These restrictions reduce the sample to 163,689 firm-years. To mitigate the effect of outliers we eliminate the top and bottom percentile of each of the variables in the model. Finally, firm-year observations where all the accrual variability measures are missing are excluded, which reduces the final sample to 78,048 firm-years.

The stock return volatility of firm $i$ at year $t$ is defined as follows: 


$$
\operatorname{VOL}_{t}^{i}=\frac{1}{D_{t}} \sum_{d=1}^{D_{t}}\left(r_{d, t}^{i}-A R_{t}^{i}\right)^{2}
$$

where $r_{d t}^{i}$ is the daily return on stock $i$, at day $d$ in year $t, A R_{t}^{i}$ is the average daily return on stock $i$ in year $t$, and $D_{t}$ is the number of trading days in year $t .^{16}$ The systematic and idiosyncratic volatilities are computed as follows. First, a factor model is used to decompose the daily stock returns into systematic and idiosyncratic return components. The factor model used is either the CAPM or the Fama-French three factor model. Malkiel and Xu (2003) also use these two models as the benchmark in their volatility decomposition. Daily individual stock returns are applied to the models to obtain the daily systematic and idiosyncratic return components. Systematic and idiosyncratic volatilities can be obtained by substituting the return components for the daily returns in equation (11). ${ }^{17}$

Recent studies (Bushee and Noe 2000; Pástor and Veronesi 2003; and Wei and Zhang 2006) use firm characteristics to explain cross-sectional differences in stock return volatility. In analyzing the relationship between the uncertainty of accounting accruals and stock return volatility, we use several control variables that have been previously identified, including return-on-equity $(R O E)$, firm size $(S I Z E)$, firm age since listing $(A G E)$, financial leverage $(L E V)$, book-to-market ratio $(B M)$ and contemporaneous stock return $(R E T U R N)$. All these variables are constructed by using the merged database. Following common practice in the literature, we eliminate the observations for each variable that are in the extreme top and bottom one percentile of each annual distribution, so as to avoid the possibility of results driven by extreme outliers. ${ }^{18}$

Wei and Zhang (2006) provide evidence that the ex post variance of stock returns is a function of $R O E$ and the variance of $R O E$. As the focus of this study is on accounting accruals (i.e., a component of accounting earnings), we only use $R O E$ as a control variable, but our empirical results remain similar when including the variance of sales as a substitute for the variance of ROE. $R O E_{t}$ in year $t$ is measured as a stock's most 
recent annual earnings divided by the book value in the last year. Following Pástor and Veronesi (2003) and Wei and Zhang (2006), who find that both profitability and its volatility are important determinants of the cross-section of volatility, we expect firms with lower $R O E$ to experience higher fluctuation of stock returns.

$A G E$ in year $t$ is defined as the logarithm of the number of months from the initial tracking date in CRSP to the current year $t$. SIZE in year $t$ is the logarithm of the firm's total market value at the end of year $t . B M$ is measured as the ratio of the book value of equity to the market value of equity. Cheung and $\mathrm{Ng}$ (1992) find that size is negatively correlated with total volatility. Pástor and Veronesi (2003) show that young firms experience higher stock return volatility. Younger and smaller firms have greater return volatility in the sense that they tend to be in more growth-oriented industries and have greater uncertainty about their future growth. The relationship between book-to-market ratio and stock return volatility is expected to be negative, because firms with greater growth opportunities are more likely to experience greater fluctuation in stock returns (also see Bushee and Noe 2000; and Wei and Zhang 2006).

RETURN in year $t$ is defined as annual buy-and-hold stock returns. Duffee (1995) advocates the use of contemporaneous returns as a control based on the notion that the realizations of expected return and risk have a common component. $L E V$ in year $t$ is defined as the sum of long-term debt and current liabilities over book value of total assets. The cross-sectional association between stock return volatility and financial leverage is expected to be positive, as highly leveraged firms are more likely to experience financial distress (see Bushee and Noe (2000), Pástor and Veronesi (2003) and Wei and Zhang (2006)). Table 1 summarizes the measurement of all variables.

\section{Table 1 about here}




\section{Descriptive Statistics}

Table 2 reports descriptive statistics for the variables used in the analysis. Results indicate that the average annual total volatility is about $14.60 \%$ while the median is $6.43 \%$. Outliers and non-normality drive the substantial difference between the mean and median, as evidenced by the values of skewness and kurtosis of 3.565 and 18.690 respectively. Similar patterns of positive skewness and significant leptokurtosis are also found in other measures of stock return volatility. Therefore, following Durnev et al. (2004), we apply a logarithmic transformation to the volatility measures. The values of skewness and kurtosis of the natural logarithm of total volatility are equal to 0.343 and 2.613 respectively, indicating the natural logarithm of these variables is more symmetric and normal. The decomposition of total volatility shows that the total variation of stock returns mainly reflects idiosyncratic volatility. On average idiosyncratic volatility explains more than $90 \%$ of total volatility, no matter whether the CAPM or Fama-French three factor model is used as the benchmark for decomposition.

Mean and median accrual earnings $(A C C E)$ are negative, while the mean and median of $A C C$ are positive. The numbers are comparable to those reported in Callen and Segal (2004). The mean of VAC_1 and VAC_2 is 0.302 and 0.120 respectively. Similar to stock return volatility measures, the variability of $A C C$ and $A C C E$ has patterns of positive skewness and significant leptokurtosis (5.270 and 35.045 for VAC_1, and 8.910 and 98.774 for $\left.V A C \_2\right)$. We therefore also employ a logarithmic transformation to these variables, resulting in reduced values of skewness and kurtosis of 0.697 and 3.018 for VAC_1, and 0.352 and 2.917 for $V A C \_2$ respectively. On average, a typical firm in our sample has market capitalization of $\$ 133$ million, a book-to-market ratio of about $0.842, R O E$ of $4.5 \%$, a tracking period in CRSP of nine years and financial leverage of $23.8 \%$ of total assets.

Table 2 about here 


\section{Decomposing Accruals Variability into Two Components}

We parallel the approach in Francis et al. (2005) for decomposing accrual uncertainty into the fundamental (innate) and discretionary portions. The discretionary component is measured as the residual from regressing accrual variability on fundamental factors as identified in prior research. Hence, we run the following cross-sectional regression to identify the two components of accruals variability:

$$
\log \left(\text { Accrual_Variability }_{i}\right)=c_{0}+\sum_{j=1}^{n} c_{j} * \text { fundamental }_{j, i}+\varepsilon_{i}
$$

where, for each firm $i, \log$ (Accrual_Variability) is the $\log$ of accrual variability representing VAC_1 or VAC_2, fundamental ${ }_{j, i}$ is the $j$ 'th fundamental factor, $j=1,2, \ldots$, $n$, where $n$ is the number of fundamental factors. A separate regression of equation (12) is estimated for each fiscal year, with each regression using all available observations of that year. The residual from equation (12) is the estimate of the discretionary component of firm $i$ 's accrual uncertainty, and the predicted values are the estimate of the fundamental component.

Following Dechow and Dichev (2002), Francis et al. (2005) identify five fundamental factors as being important in explaining accrual uncertainty (firm size, cash flow variability, sales variability, length of operating cycle, and incidence of negative earnings realizations). Following Francis et al. (2005), we would expect smaller firms, and firms with greater cash flow volatility, longer operating cycles, and a greater incidence of losses, to have higher accrual uncertainty. Firm size is proxied by the log of total assets $(T A) .{ }^{19}$ Cash flow variability, $\log (V C F E)$, is measured as the log of the sample variance of the firm's rolling five-year cash flows from operations, scaled by book values of equity. Sales variability, $\log (V R E V)$, is the $\log$ of the sample variance of the firm's rolling five-year sales revenues, scaled by total assets. Operating cycle, (OperCycle), is the log of the sum of the firm's accounts receivable and inventory turnover (in days). Incidence of negative earnings realizations, (NegEarn), is calculated as the firm's proportion of losses over the prior five years. Table 2, Panel D reports descriptive information on the five fundamental factors. The sample mean 
values are 5.462 for $\log (T A),-3.968$ for $\log (V C F E)$, and -5.168 for $\log (V R E V)$. Operating cycle has a mean of 165 days, with a median of 136 days. Firms have losses in about $21 \%$ of the years.

Table 3 reports the mean regression coefficient from the annual estimation of equation (12). The reported $t$-statistics are based on the time-series standard errors of the 31 coefficient estimates. In all cases, we find the expected sign on the summary indicators of fundamental determinates, and all indicators are individually significant in explaining accruals variability (with $t$-statistics, in absolute value, ranging from 2.93 to 55.17). The mean of the fundamental component is -2.312 for VAC_1 and -4.249 for VAC_2 respectively, compared to an expected zero mean value for the discretionary component. As a whole, the results show that the fundamental factors explain a significant portion of cross-sectional variation in accruals variability, as the explanatory power averages $21.4 \%$ for $V A C \_1$ and $69.8 \%$ for $V A C \_2$ across the yearly estimators.

\section{Table 4 about here}

\section{Correlation Analysis}

We first analyse the pair-wise correlation between five measures of stock return volatility, accrual variability and other control variables. ${ }^{20}$ As a natural consequence of using a large dataset, most of the correlations are statistically significant, but no pairwise correlation between accrual variability measures and control variables exceeds 0.32 in absolute values. VAC_1 and VAC_2 are positively related to total volatility, with correlation coefficients of 0.316 and 0.384 , respectively. The correlation coefficient of the fundamental component of accrual variability and total volatility (0.546 for $V A C_{-} 1$ and 0.448 for $V A C_{-} 2$ ) is much higher than that for the discretionary component ( 0.056 for $V A C \_1$ and 0.008 for VAC_2). Overall, the correlation results provide preliminary evidence that supports a consistent positive relationship between accrual variability measures and future stock return volatility, as 
well as the expectation that the relationship is stronger for the fundamental component of accrual variability than for the discretionary component.

\section{RESULTS}

\section{Accrual Variability and Total Volatility}

Given the significant skewness and leptokurtosis present in our stock return volatility measures, we apply a logarithmic transformation to these measures to reduce the potential impact of outliers and non-normality on our analysis, as discussed before. To further ease interpretation of our results, we standardize all of our variables by subtracting the sample mean and dividing by the sample standard deviation. Thus, all regression coefficients are presented in comparable units. None of these transformations has a qualitative impact on our results.

After putting the data through these two transformations, we begin with a set of pooled time-series and cross-sectional regressions of total volatility on accounting accruals. To address the potential confounding effect of correlated omitted variables, we estimate the following equation that incorporates the control variables discussed above:

$$
\log \left(\operatorname{VOL}_{i, t}\right)=\beta_{0}+\beta \log \left(\text { Accrual_Variability }_{i, t-1}\right)+\sum_{j=1}^{n} \gamma_{j} * \operatorname{control}_{j, i}+\varepsilon_{i, t}
$$

where, for each firm $i, V O L_{i}$ is the volatility measure of stock $i$ in year $t$, as defined in (11), control $_{j, i}$ is the $j$ 'th control variable, $j=1,2, \ldots, n$, where $n$ is the number of control variables. In analyzing the relationship between the uncertainty of accounting accruals and stock return volatility, we use several control variables that have been previously identified, including lagged accounting earnings ( $R O E)$, lagged firm size $(S I Z E)$, lagged firm age since listing on CRSP $(A G E)$, lagged financial leverage ( $L E V)$, lagged book-to-market ratio $(B M)$ and contemporaneous stock return (RETURN). Note that all variables of interest have been standardized to facilitate interpretation of the results. It is also worthy of note that all independent variables, with the exception 
of the contemporary return variable $R_{i, t}$, are lagged by one period to allow the market sufficient time to incorporate financial statement information into stock return volatility, and avoid picking up a merely contemporary association between stock return volatility and accounting accruals. We calculate $t$-statistics using standard errors corrected for both clustering by firm and clustering by year. Correlation of the observations across time for a given firm and correlation across firms for a given year could result in biased standard errors in our panel dataset regressions. Petersen (2009) surveys and evaluates the variety of estimation techniques researchers have devised to mitigate this problem, and suggests the use of the above approach.

Table 4 reports estimated coefficients together with $t$-statistics in parentheses based on two-way clustering. The results support $\mathbf{H} 1$, indicating that future stock return volatility is significantly positively associated with the variability of accounting accruals. The coefficients on $V A C \_1$ and $V A C \_2$ are statistically significant in all specifications. When $V A C \_1$ or VAC_2 is the only variable included, the estimated coefficients are $0.303(t=13.48)$ and $0.347(t=22.28)$, indicating that a one standard deviation increase in the $\log$ of accrual variability results in a more than $30 \%$ increase in the log of stock return volatility. When combined with all control variables, the magnitude of the slope coefficient of accrual variability decreases to $0.144(t=5.79)$ and $0.192(t=13.97)$, but it remains significant. Most control variables used in the regression have significant coefficients. Evidence of a significant negative coefficient for ROE confirms the results in Wei and Zhang (2006). Consistent with Pástor and Veronesi (2003), small, young and growth firms tend to have more volatile returns, as indicated by the significant and consistent signs of SIZE, AGE and BM.

\section{Table 4 about here}

\section{Fundamental vs. Discretionary Component of Accrual Variability}

Having established a relationship between stock return volatility and accrual variability, we now turn to examine the second hypothesis in our study. We 
decompose accrual variability into the fundamental and discretionary components, following Francis et al. (2005). Table 5 reports the results from estimating the following regression model:

$$
\log \left(V O L_{i, t}\right)=\beta_{0}+\beta_{1} \log \left(\text { FundVAC }_{i, t-1}\right)+\beta_{2} \log \left(\text { DiscVAC }_{i, t-1}\right)+\sum_{j=1}^{n} \gamma_{j} * \operatorname{control}_{j, i}+\varepsilon_{i, t}(14
$$

where, FundVAC and DiscVAC are the fundamental and discretionary components of accrual variability as discussed above. As we use two measures of accounting accruals, we use FundVAC_1 (DiscVAC_1) and FundVAC_2 (DiscVAC_2) to represent the fundamental (discretionary) component of $V A C_{-} 1$ and VAC_2 respectively.

We first discuss the explanatory power of the fundamental and discretionary components. When the fundamental component is the only variable included, the estimated coefficient is 0.524 for FundVAC_1 $(t=24.03)$ and 0.416 for FundVAC_2 $(t=28.46)$ respectively, indicating that a one standard deviation increase in the fundamental component of accrual variability results in a more than $40 \%$ increase in the log of stock return volatility. However, the relationship between the discretionary component of accrual variability with future stock return volatility is noticeably weaker. Although the estimated coefficient is statistically significant ( 0.069 for DiscVAC_1 with a $t$-value of 5.19, and 0.005 for DiscVAC_2 with a $t$-value of 0.56), its magnitude implies far lower economic significance in that a one standard deviation increase in the discretionary component results in less than a $7 \%$ increase in the log of stock return volatility. The above results do not alter when all control variables are included.

Overall, the above results show that the positive relationship between accrual variability and future stock return volatility is mostly sourced from the fundamental portion. These findings are consistent with Kim and Qi (2010) and Liu and Wysocki (2007) and suggest that the uncertainty reflected in accruals contributes to the fluctuation of future stock returns. The predictive content of accrual uncertainty is 
associated with a firm's fundamental uncertainty rather than the discretionary component, (i.e., that part which is most likely to reflect accounting choices, implementation decisions and managerial opportunism). Our results also add weight to the argument that capital markets place relatively little weight on accounting data which has been subjected to managerial intervention, as distinct from that which reflects underlying fundamentals.

\section{Table 5 about here}

\section{Systematic Volatility vs. Idiosyncratic Volatility}

Fundamental variables can cause both systematic and idiosyncratic variation in stock returns. Although it is widely held that most fundamental variables cause idiosyncratic volatility at the firm level, the relative importance of the uncertainty of non-accounting information on systematic versus idiosyncratic volatility is ultimately an empirical issue. We therefore separately examine the empirical cross-sectional relationship of accruals variability with systematic and idiosyncratic volatility. Similar to Malkiel and Xu (2003), we rely on the CAPM and the Fama-French three factor model (Fama and French 1993, 1996) as benchmarks for volatility decomposition.

For each measure of systematic or idiosyncratic volatility, we estimate the coefficients in regression (13) and (14). For brevity, we focus on the influence of our accounting variability measure on systematic and idiosyncratic volatility estimated from the Fama-French three factor model. The estimated coefficients are shown in Tables 6 and 7. The results support the view that a typical firm's volatility of accounting accruals is associated with differences in both the systematic and idiosyncratic components of volatility. The coefficients on $V A C \_1$ and $V A C \_2$ are significantly positive in all specifications of either systematic or idiosyncratic volatility. For instance, when combined with all control variables, the magnitudes of the VAC_1 (VAC_2) coefficient are $0.106(0.118)$ for systematic volatility and $0.162(0.178)$ for idiosyncratic volatility, both with significant $t$-statistics. As idiosyncratic volatility 
accounts for over $90 \%$ of total volatility, it is not surprising that the main results are repeated for idiosyncratic volatility. However, the adjusted $\mathrm{R}^{2}$ for systematic volatility is much smaller than for idiosyncratic volatility, $8.9 \%$ (11.2\%) compared to $39.3 \%$ (45.4\%). The higher explanatory power of accrual volatility for idiosyncratic volatility is consistent with evidence in Campbell (1991) and Campbell and Ammer (1993) that expected-return news dominates cash-flow news in driving aggregate stock returns, and Vuolteenaho (2002) and Callen and Segal (2004) that payoff news is the main factor that drives stock returns at the firm level.

We also disentangle the relationship of the fundamental and discretionary components of accrual variability with future systematic and idiosyncratic volatility. The coefficients on FundVAC are qualitatively similar to those reported for $V A C$. When no controls are included, the magnitudes of the FundVAC_1 (FundVAC_2) coefficient are $0.186(0.170)$ for systematic volatility and $0.532(0.426)$ for idiosyncratic volatility, suggesting that the fundamental component has a stronger relationship with idiosyncratic volatility than with systematic volatility. However, in tests using DiscVAC, its relationship with both systematic and idiosyncratic volatility is substantially weaker than FundVAC. For instance, the estimated coefficient on DiscVAC_1 is $0.070(0.012)$ for systematic (idiosyncratic) volatility, compared to a larger estimated coefficient on FundVAC_1 of 0.186 (0.532). Thus, the results are consistent with $\mathrm{H} 4$ that the relationship with future systematic and idiosyncratic volatility is stronger for the fundamental component of accruals uncertainty than for the discretionary component.

\section{Tables 6 and 7 about here}

\section{ADDITIONAL TESTS}

We carefully consider the sensitivity of our results to a variety of institutional factors and estimation approaches. The robustness analysis generates qualitatively similar results to those presented above, namely an almost identical pattern of signs and 
statistical significance is established in all of the checks. Space constraints limit the following discussion to a focus on total volatility with the discretionary and fundamental components of accrual variability, but the results for all other specifications are similar and are available upon request.

\section{NASDAQ versus NYSE/Amex Stocks}

We separately examine results for NASDAQ-traded stocks from those traded on the NYSE/AMEX for several reasons. Schwert (2002) demonstrates that the NASDAQ portfolio became unusually volatile relative to the S\&P portfolio over the six-year period between 1995 and 2001. Pástor and Veronesi (2006) also find that NASDAQ stocks became more volatile at the height of the NASDAQ 'internet bubble'. It is also well documented that different markets provide different degrees of liquidity (Christie and Schultz 1994) and cost of executing trades (Huang and Stoll 1996), both of which may differentially influence our volatility analyses. Of our full sample, 33\% of all firm-years are from NASDAQ while the rest come from NYSE/AMEX. We therefore repeat the above analysis for each sub-sample. Without exception, the results support our hypotheses irrespective of whether we examine NASDAQ firms or NYSE/AMEX firms.

\section{Measuring Accruals using Statement of Cash Flow Data}

Our study uses total accruals estimated from the balance sheet, because cash flow statements data did not become generally available until 1987. Hribar and Collins (2002) illustrate that mergers and acquisitions, divestitures and foreign currency translation can introduce measurement error into accrual measures estimated from income statements and balance sheets, and sometimes can completely alter statistical relations. To address this potential error, we utilize statements of cash flow to estimate accruals as per Hribar and Collins (2002). Specifically, we measure operating cash flow as operating cash flow minus the cash portion of discontinued operations and extraordinary items, and accruals as earnings minus operating cash flow. The resulting inferences remain qualitatively similar to the main results in the 
paper.

New Listing, Loss Firm and Technology Firm Effects

Fama and French (2004) provide support for the explanation that trends in the entry and exit of firms over time could be responsible for the increase in idiosyncratic return volatility. Wei and Zhang (2006) also attribute most of the upward trend in idiosyncratic volatility to new listings. Since newer firms have greater uncertainty about fundamentals and comprise a growing component of the set of all publicly traded firms, it is plausible that the relationship between stock return volatility and the volatility of accounting accruals could simply reflect the relative importance of these newly-listed (and more volatile) firms. To explore this conjecture, we separate firms listed on the three exchanges before 1980 ('old firms') from those after 1980 ('new firms'), and the results for both subsamples are presented in Panel A and Panel B of Table 8. The results suggest that the FundVAC_1 and FundVAC_2 coefficients continue to be significantly positive for 'new firms'. Indeed, the magnitude of the FundVAC_1 and FundVAC_2 coefficients for 'new firms' is smaller than that for 'old firms', but remains economically and statistically significant. Hence, the link between stock return volatility and accrual variability documented thus far does not appear to be driven by an increase in new listings.

Collins, Pincus and Xie (1999) and Givoly and Hayn (2000) document a monotonic increase in the frequency of losses over the last five decades, while Hayn (1995) shows that the market reaction to a loss is systematically different to the response to positive earnings. To the extent that accrual variability of loss firms is higher than profit firms, the relationship between accrual variability and stock return volatility may be attributable to the effect of an increasing number of loss firms in recent times. Hence, we classify observations into loss firms (Panel C) and profit firms (Panel D) according to their earnings in a specific fiscal year. In the case of losses, the relationship between the fundamental component of accrual variability and stock return volatility is weaker than profitable peers ( 0.246 compared to 0.351 for 
FundVAC_1, and 0.156 compared to 0.270 for FundVAC_2). Overall, our results appear robust to firms that make losses in the sample.

Given the increasing number of high technology firms during our sample period (especially during the so-called dot com boom years around 2000), we investigate whether empirical evidence of a positive relationship between accrual variability and stock return volatility may be primarily attributable to this sub-set of firms (Chan et al. 2001; Schwert 2002). We therefore re-estimate our results after deleting firms classified as being in technology-intensive industries, namely those in the three digit SIC codes 283, 357, 360-368, 481, 737 and 873 (Francis and Schipper 1999). This group amounts to approximately one-sixth of our total sample. Results reported in Panel E of Table 8 indicate that the empirical results are not a by-product of the increased importance of high-technology firms.

\section{Table 8 about here}

\section{Alternative Decomposition of Accrual Variability}

The primary approach adopted in this paper to partition total accrual variability into fundamental and discretionary components follows Francis et al. (2005) and uses five variables representing economic fundamentals. While this approach is useful in that it facilitates statistical inferences on the differential impacts of the two components of accrual volatility, this approach has potential drawbacks.

For example, a recent study by Hribar and Nichols (2007) suggests that the commonly used unsigned measures of accrual quality (e.g. the variance or the absolute value of discretionary accruals measures) tends to be associated with firm characteristics such as firm size, sales growth, leverage, book-to-market ratios, cash from operations, volatility of sales, volatility of earnings, and volatility of cash flows. By simulation analysis, Hribar and Nichols (2007) highlight the threat of correlated omitted variables in research designs that use unsigned measures of accruals quality and the 
risk of incorrect statistical inferences. To mitigate the concern of correlated omitted variables, we also include four additional determinants of fundamental accruals variables as reported in Hribar and Nichols (2007). These additional controls are sales growth (revenue ${ }_{\mathrm{t}} /$ revenue $_{\mathrm{t}-1}$ ), leverage (total debt over total assets), book-to-market ratios and cash flows from operations. We repeat our disaggregation of accruals variability and find the results (not tabulated) remain qualitatively similar to those previously documented.

Our second sensitivity check involves estimating equation (13) and (14) using fixedand random-effects models. The main advantage of using fixed- and random-effects models is that these two approaches allows us to account for the 'individuality' of each cross-sectional unit (e.g. firm, time) by letting the intercepts vary for each cross-sectional unit but still assuming that the slope coefficients are constant or random across firms. These two approaches therefore control for all unobservable firm-specific characteristics that potentially contribute to the fundamental component. Untabulated results based on fixed- and random-effect regression are quantitatively and qualitatively similar to those obtained from the original specification.

\section{Fama-MacBeth Regressions}

The inferences above about the association between accrual variability and stock return volatility are based on a pooled time-series and cross-sectional regression, where multiple annual observations for the same firm are used. However, as stock return volatility is persistent (Schwert (1989)), the standard errors of the coefficients in equation (13) and (14) may be biased downward. To mitigate concerns about serial correlation of the standard errors, we examine the robustness of our results to using the Fama-MacBeth estimation approach. We first estimate coefficients in equation (13) or (14) for each year in the sample period. The resulting parameter estimates are time-series averages of the estimated cross-sectional coefficients for all years. Since return volatility is autocorrelated and heteroscedastic, the annual estimates might inherit these statistical properties as well, so $t$-statistics are adjusted for 
autocorrelation and conditional heteroskedasticity (Newey and West 1987). Comparing the results of these estimates (untabulated) to those of the pooled regressions, the magnitude of the accrual variability coefficient without any control variables, for example, declines to 0.268 (VAC_1) and 0.317 (VAC_2), but still with a significant $t$-statistic of 8.06 (VAC_1) and 10.24 (VAC_2) respectively.

\section{Controlling for Lagged Volatility}

Our prior estimates of Equation (13) and (14) do not include the prior level of stock return volatility (or its components) as a control variable, consistent with most cross-sectional volatility studies (Bushee and Noe 2000; Pástor and Veronesi 2003; Ferreira and Laux 2007). This is because our focus is on explaining the level of volatility rather than the change in volatility (see Bushee and Noe (2000) for additional discussion). Furthermore, even though the persistent nature of stock return volatility could cause the residuals from a regression of the level of volatility to be serially correlated, such residual autocorrelation problem can be corrected by using the Newey-West (1987) or Petersen (2009) adjusted standard errors, as we do in the results reported above.

However, we also examine the sensitivity of our results to the inclusion of lagged stock return volatility, and find our main results continue to hold. Take VAC_1 as an example. When all control variables including lagged volatility are included, the regression coefficients are 0.076 for FundVAC_1 $(t=6.16)$ and 0.012 for DiscVAC_1 $(t=2.12)$ respectively. We also confirm the persistence of stock return volatility, as evidenced by a significant estimated coefficient of lagged volatility being equal to $0.687(t=28.72)$.

\section{CONCLUSION}

In this paper, we initially extend the accounting version of the Campbell-Shiller model to show that when accounting accruals are more uncertain, the future stock 
return of the firm is more volatile, ceteris paribus. Our approach extends the models of Callen and Segal (2004) and Vuolteenaho (2002), and our focus on the variability of accruals contrast with prior research which examines accrual levels and/or the variability of the unexplained component of an accruals model (Dechow and Dichev 2002). We then demonstrate empirical support for the predicted link between stock return volatility and accrual variability, even after controlling for other relevant firm-specific variables. Put simply, the uncertainty evident in accounting accruals is reflected in subsequent period return fluctuations. This result is also robust to a battery of additional analysis, and is evident for both the systematic and idiosyncratic components of return volatility.

Given prior evidence suggesting that accounting accruals contain both fundamental (sourced from the firm's business model and operating environment) and discretionary (sourced from managerial choices) components, we apply the process suggested by Francis et al. (2005) to decompose accrual variability into these two components. We find the positive relationship between accrual variability and future stock return volatility is dominated by the fundamental portion of accruals. Hence, it appears that the predictive content of accrual uncertainty is associated with a firm's fundamental uncertainty, rather than any volatile discretionary component which is more likely to reflect accounting choices, implementation decisions and managerial opportunism. This result adds weight to the view that the primary influence of accrual information on measures such as the cost of capital is likely to reflect the link between accruals and fundamentals, rather than any consistent effect via managerial intervention in the accrual process. 


\section{Appendix A: Details in Extending the Callen-Segal Model (2004)}

First, calculating the conditional expectation of $A C C_{t+j}$ at time $t$ :

$$
\begin{aligned}
& E_{t}\left(A C C_{t+j}\right) \\
& =E_{t}\left(a+\theta * A C C_{t+j-1}+e_{t+j}\right) \\
& =a+\theta E_{t}\left(A C C_{t+j-1}\right)+E_{t}\left(e_{t+j}\right) \\
& =a+\theta E_{t}\left(a+\theta * A C C_{t+j-2}+e_{t+j-1}\right) \\
& =a(1+\theta)+\theta^{2} E_{t}\left(A C C_{t+j-2}\right) \\
& =\ldots \ldots \\
& =a\left(1+\theta+\theta^{2}+\ldots+\theta^{j-1}\right)+\theta^{j} E_{t}\left(A C C_{t}\right) \\
& =a\left(1-\theta^{j}\right) /(1-\theta)+\theta^{j} A C C_{t}
\end{aligned}
$$

Similarly, we have,

$$
E_{t-1}\left(A C C_{t+j}\right)=a\left(1-\theta^{j+1}\right) /(1-\theta)+\theta^{j+1} A C C_{t-1} .
$$

Given (A1) and (A2), the change of expectation of $A C C_{t+j}$ can be written as,

$$
\begin{aligned}
& \Delta E_{t}\left(A C C_{t+j}\right)=E_{t}\left(A C C_{t+j}\right)-E_{t-1}\left(A C C_{t+j}\right) \\
& =\left[a\left(1-\theta^{j}\right) /(1-\theta)+\theta^{j} A C C_{t}\right]-a\left(1-\theta^{j+1}\right) /(1-\theta)-\theta^{j+1} A C C_{t-1} . \\
& =\theta^{j}\left(A C C_{t}-a-\theta * A C C_{t-1}\right) \\
& =\theta^{j} e_{t}
\end{aligned}
$$

Summing up the discounted change in the change of expectation of $A C C_{t+j}$, we obtain:

$$
\Delta E_{t} \sum_{j=0}^{\infty} \rho^{j} A C C_{t+j}=\frac{1}{1-\rho \theta} e_{t},(\mathrm{~A} 3)
$$

Therefore, we have the representation of equation (4),

$$
\operatorname{Var}_{t-1}\left(\Delta E_{t} \sum_{j=0}^{\infty} \rho^{j} A C C_{t+j}\right)=\frac{1}{(1-\rho \theta)^{2}} \operatorname{Var}_{t-1}\left(e_{t}\right) .
$$




\section{Appendix B: Details in Extending the Vuolteenaho Model (2002)}

First, calculating the conditional expectation of $C F E_{t+j}$ at time $t$ :

$$
\begin{aligned}
& E_{t}\left(C F E_{t+j}\right) \\
& =E_{t}\left(b+\gamma * C F E_{t+j-1}+v_{t+j}\right) \\
& =b+\gamma E_{t}\left(C F E_{t+j-1}\right)+E_{t}\left(v_{t+j}\right) \\
& =b+\gamma E_{t}\left(b+\gamma * C F E_{t+j-2}+v_{t+j-1}\right) \\
& =b(1+\gamma)+\gamma^{2} E_{t}\left(C F E_{t+j-2}\right) \\
& =\ldots \ldots \\
& =b\left(1+\gamma+\gamma^{2}+\ldots+\gamma^{j-1}\right)+\gamma^{j} E_{t}\left(C F E_{t}\right) \\
& =b\left(1-\gamma^{j}\right) /(1-\gamma)+\gamma^{j} C F E_{t}
\end{aligned}
$$

We denote that

$$
\begin{aligned}
& E_{t}\left(C F E_{t+j}\right)=f(j)=b\left(1-\gamma^{j}\right) /(1-\gamma)+\gamma^{j} C F E_{t} \\
& E_{t}\left(C F E_{t+j-1}\right)=f(j-1)=b\left(1-\gamma^{j-1}\right) /(1-\gamma)+\gamma^{j-1} C F E_{t} \\
& E_{t}\left(C F E_{t+1}\right)=f(1)=b+\gamma C F E_{t}
\end{aligned}
$$

Then, we calculate and denote the conditional expectation of $C F E_{t+j}$ at time $t-1$ :

$$
\begin{aligned}
& E_{t-1}\left(C F E_{t+j}\right) \\
& =g(j+1) \\
& =E_{t-1}\left(b \frac{1-\gamma^{j}}{1-\gamma}+\gamma^{j} C F E_{t}\right) \\
& =E_{t-1}\left[b \frac{1-\gamma^{j}}{1-\gamma}+\gamma^{j}\left(b+\gamma * C F E_{t-1}+v_{t}\right)\right] \\
& =b\left(1-\gamma^{j+1}\right) /(1-\gamma)+\gamma^{j+1} C F E_{t-1} \\
& E_{t-1}\left(C F E_{t+j-1}\right)=g(j)=b\left(1-\gamma^{j}\right) /(1-\gamma)+\gamma^{j} C F E_{t-1} \\
& E_{t-1}\left(C F E_{t}\right)=g(1)=b+\gamma C F E_{t-1}
\end{aligned}
$$


Now we calculate the conditional expectation of $A C C E_{t+j}$ at time $t$ :

$$
\begin{aligned}
& E_{t}\left(A C C E_{t+j}\right) \\
& =E_{t}\left(\alpha+\beta A C C E_{t+j-1}+\theta C F E_{t+j}+u_{t+j}\right) \\
& =a+\beta E_{t}\left(A C C E_{t+j-1}\right)+\theta E_{t}\left(C F E_{t+j}\right)+E_{t}\left(u_{t+j}\right) \\
& =a+\beta E_{t}\left(A C C E_{t+j-1}\right)+\theta f(j) \\
& =a+\beta E_{t}\left(\alpha+\beta A C C E_{t+j-2}+\theta C F E_{t+j-1}+u_{t+j-1}\right)+\theta f(j) \\
& =a(1+\beta)+\beta^{2} E_{t}\left(A C C E_{t+j-2}\right)+\theta f(j)+\theta \beta f(j-1) \\
& =a(1+\beta)+\beta^{2} E_{t}\left(\alpha+\beta A C C E_{t+j-3}+\theta C F E_{t+j-2}+u_{t+j-2}\right)+\theta f(j)+\theta \beta f(j-1) \\
& =a\left(1+\beta+\beta^{2}\right)+\beta^{3} E_{t}\left(A C C E_{t+j-3}\right)+\theta f(j)+\theta \beta f(j-1)+\theta \beta^{2} f(j-2) \\
& =\ldots \ldots \\
& =a\left(1+\beta+\beta^{2}+\ldots+\beta^{j-1}\right)+\beta^{j} A C C E_{t}+\left[\theta f(j)+\theta \beta f(j-1)+\theta \beta^{2} f(j-2)+\ldots+\theta \beta^{j-1} f(1)\right] \\
& =a\left(1-\beta^{j}\right) /(1-\beta)+\beta^{j} A C C E_{t}+F(1)
\end{aligned}
$$

Where $F(1)=\theta f(j)+\theta \beta f(j-1)+\theta \beta^{2} f(j-2)+\ldots+\theta \beta^{j-1} f(1)$

Similarly we calculate the conditional expectation of $A C C E_{t+j}$ at time $t-1$ :

$$
\begin{aligned}
& E_{t-1}\left(A C C E_{t+j}\right) \\
& =E_{t-1}\left(\alpha+\beta A C C E_{t+j-1}+\theta C F E_{t+j}+u_{t+j}\right) \\
& =a+\beta E_{t-1}\left(A C C E_{t+j-1}\right)+\theta E_{t-1}\left(C F E_{t+j}\right)+E_{t-1}\left(u_{t+j}\right) \\
& =a+\beta E_{t-1}\left(A C C E_{t+j-1}\right)+\theta g(j+1) \\
& =a+\beta E_{t-1}\left(\alpha+\beta A C C E_{t+j-2}+\theta C F E_{t+j-1}+u_{t+j-1}\right)+\theta g(j+1) \\
& =a(1+\beta)+\beta^{2} E_{t-1}\left(A C C E_{t+j-2}\right)+[\theta g(j+1)+\theta \beta g(j)] \\
& =a(1+\beta)+\beta^{2} E_{t-1}\left(\alpha+\beta A C C E_{t+j-3}+\theta C F E_{t+j-2}+u_{t+j-2}\right)+[\theta g(j+1)+\theta \beta g(j)] \\
& =a\left(1+\beta+\beta^{2}\right)+\beta^{3} E_{t-1}\left(A C C E_{t+j-3}\right)+\left[\theta g(j+1)+\theta \beta f(j)+\theta \beta^{2} g(j-1)\right] \\
& =\ldots \ldots \\
& =a\left(1+\beta+\beta^{2}+\ldots+\beta^{j-1}\right)+\beta^{j} E_{t-1}\left(A C C E_{t}\right)+\left[\theta g(j+1)+\theta \beta g(j)+\theta \beta^{2} g(j-1)+\ldots+\theta \beta^{j-1} g(2)\right] \\
& =a\left(1+\beta+\beta^{2}+\ldots+\beta^{j-1}\right)+\beta^{j} E_{t-1}\left(\alpha+\beta A C C E_{t-1}+\theta C F E_{t}+u_{t}\right) \\
& +\left[\theta g(j+1)+\theta \beta g(j)+\theta \beta^{2} g(j-1)+\ldots+\theta \beta^{j-1} g(2)\right] \\
& =a\left(1+\beta+\beta^{2}+\ldots+\beta^{j-1}\right)+\beta^{j+1} A C C E_{t-1}+\left[\theta g(j+1)+\theta \beta g(j)+\ldots+\theta \beta^{j-1} g(2)+\theta \beta^{j} g(1)\right] \\
& =a\left(1-\beta^{j+1}\right) /(1-\beta)+\beta^{j+1} A C C E_{t-1}+F(2)
\end{aligned}
$$

Where $F(2)=\theta g(j+1)+\theta \beta g(j)+\theta \beta^{2} g(j-1)+\ldots+\theta \beta^{j} g(1)$ 
We calculate $F(1)$ and $F(2)$ respectively.

$$
\begin{aligned}
& F(1)=\theta f(j)+\theta \beta f(j-1)+\theta \beta^{2} f(j-2)+\ldots+\theta \beta^{j-1} f(1) \\
& =\theta\left[\left(b \frac{1-\gamma^{j}}{1-\gamma}+\gamma^{j} C F E_{t}\right)+\beta\left(b \frac{1-\gamma^{j-1}}{1-\gamma}+\gamma^{j-1} C F E_{t}\right)+\cdots++\beta^{j-1}\left(b \frac{1-\gamma}{1-\gamma}+\gamma C F E_{t}\right)\right] \\
& =\frac{b \theta}{1-\gamma}\left[\left(1-\gamma^{j}\right)+\beta\left(1-\gamma^{j-1}\right)+\cdots+\beta^{j-1}(1-\gamma)\right]+\theta C F E_{t}\left[\gamma^{j}+\beta \gamma^{j-1}+\cdots+\beta^{j-1} \gamma\right] \\
& =\frac{b \theta}{1-\gamma}\left[\left(1+\beta+\cdots+\beta^{j-1}\right)-\left(\gamma^{j}+\beta \gamma^{j-1}+\cdots+\beta^{j-1} \gamma\right)\right]+\theta C F E_{t}\left[\gamma^{j}+\beta \gamma^{j-1}+\cdots+\beta^{j-1} \gamma\right] \\
& =\frac{b \theta}{1-\gamma}\left[\frac{1-\beta^{j}}{1-\beta}-\frac{\gamma\left(\gamma^{j}-\beta^{j}\right)}{\gamma-\beta}\right]+\theta C F E_{t} \frac{\gamma\left(\gamma^{j}-\beta^{j}\right)}{\gamma-\beta}
\end{aligned}
$$

$F(2)=\theta g(j+1)+\theta \beta g(j)+\theta \beta^{2} g(j-1)+\ldots+\theta \beta^{j} g(1)$

$=\theta\left[\left(b \frac{1-\gamma^{j+!}}{1-\gamma}+\gamma^{j+1} C F E_{t+1}\right)+\beta\left(b \frac{1-\gamma^{j}}{1-\gamma}+\gamma^{j} C F E_{t-1}\right)+\cdots++\beta^{j}\left(b \frac{1-\gamma}{1-\gamma}+\gamma C F E_{t-1}\right)\right]$

$=\frac{b \theta}{1-\gamma}\left[\left(1-\gamma^{j+1}\right)+\beta\left(1-\gamma^{j}\right)+\cdots+\beta^{j}(1-\gamma)\right]+\theta C F E_{t-1}\left[\gamma^{j+!}+\beta \gamma^{j}+\cdots+\beta^{j} \gamma\right]$

$=\frac{b \theta}{1-\gamma}\left[\left(1+\beta+\cdots+\beta^{j}\right)-\left(\gamma^{j+1}+\beta \gamma^{j}+\cdots+\beta^{j} \gamma\right)\right]+\theta C F E_{t-1}\left[\gamma^{j+1}+\beta \gamma^{j}+\cdots+\beta^{j} \gamma\right]$

$=\frac{b \theta}{1-\gamma}\left[\frac{1-\beta^{j+1}}{1-\beta}-\frac{\gamma\left(\gamma^{j+1}-\beta^{j+1}\right)}{\gamma-\beta}\right]+\theta C F E_{t-1} \frac{\gamma\left(\gamma^{j+1}-\beta^{j+1}\right)}{\gamma-\beta}$

Given (B1) and (B2), the change of expectation of $R O E_{t+j}$ can be written as,

$$
\begin{aligned}
& \Delta E_{t}\left(A C C E_{t+j}\right)=E_{t}\left(A C C E_{t+j}\right)-E_{t-1}\left(A C C E_{t+j}\right) \\
& =\left[a\left(1-\beta^{j}\right) /(1-\beta)+\beta^{j} A C C E_{t}+F(1)\right]-\left[a\left(1-\beta^{j+1}\right) /(1-\beta)+\beta^{j+1} A C C E_{t-1}+F(2)\right] \\
& =a\left(\beta^{j+1}-\beta^{j}\right) /(1-\beta)+\beta^{j}\left(A C C E_{t}-\beta A C C E_{t-1}\right)+F(1)-F(2) \\
& =a\left(\beta^{j+1}-\beta^{j}\right) /(1-\beta)+\beta^{j}\left(a+\theta C F E_{t}+u_{t}\right)+\left[\frac{b \theta}{1-\gamma}\left[\frac{1-\beta^{j}}{1-\beta}-\frac{\gamma\left(\gamma^{j}-\beta^{j}\right)}{\gamma-\beta}\right]+\theta C F E_{t} \frac{\gamma\left(\gamma^{j}-\beta^{j}\right)}{\gamma-\beta}\right] \\
& -\left[\frac{b \theta}{1-\gamma}\left[\frac{1-\beta^{j+1}}{1-\beta}-\frac{\gamma\left(\gamma^{j+1}-\beta^{j+1}\right)}{\gamma-\beta}\right]+\theta C F E_{t-1} \frac{\gamma\left(\gamma^{j+1}-\beta^{j+1}\right)}{\gamma-\beta}\right] \\
& =a \beta^{j}-a \beta^{j}+\beta^{j} \theta C F E_{t}+\beta^{j} u_{t}+\left[\frac{b \theta}{1-\gamma}\left[\frac{1-\beta^{j}}{1-\beta}-\frac{\gamma\left(\gamma^{j}-\beta^{j}\right)}{\gamma-\beta}\right]+\theta \frac{\gamma\left(\gamma^{j}-\beta^{j}\right)}{\gamma-\beta}\left(b+\gamma C F E_{t-1}+v_{t}\right)\right] \\
& -\left[\frac{b \theta}{1-\gamma}\left[\frac{1-\beta^{j+1}}{1-\beta}-\frac{\gamma\left(\gamma^{j+1}-\beta^{j+1}\right)}{\gamma-\beta}\right]+\theta C F E_{t-1} \frac{\gamma\left(\gamma^{j+1}-\beta^{j+1}\right)}{\gamma-\beta}\right]
\end{aligned}
$$




$$
\begin{aligned}
& =\beta^{j} \theta\left(b+\gamma C F E_{t-1}+v_{t}\right)+\beta^{j} u_{t} \\
& +\left\{\frac{b \theta}{1-\gamma}\left[\frac{1-\beta^{j}}{1-\beta}-\frac{\gamma\left(\gamma^{j}-\beta^{j}\right)}{\gamma-\beta}\right]+b \theta \frac{\gamma\left(\gamma^{j}-\beta^{j}\right)}{\gamma-\beta}+\gamma \theta \frac{\gamma\left(\gamma^{j}-\beta^{j}\right)}{\gamma-\beta} C F E_{t-1}+\theta \frac{\gamma\left(\gamma^{j}-\beta^{j}\right)}{\gamma-\beta} v_{t}\right\} \\
& -\left\{\frac{b \theta}{1-\gamma}\left[\frac{1-\beta^{j+1}}{1-\beta}-\frac{\gamma\left(\gamma^{j+1}-\beta^{j+1}\right)}{\gamma-\beta}\right]+\theta C F E_{t-1} \frac{\gamma\left(\gamma^{j+1}-\beta^{j+1}\right)}{\gamma-\beta}\right\} \\
& =\beta^{j} \theta b+\gamma \beta^{j} \theta C F E_{t-1}+\beta^{j} \theta v_{t}+\beta^{j} u_{t}+\left[\theta \frac{\gamma\left(\gamma^{j}-\beta^{j}\right)}{\gamma-\beta} v_{t}+\gamma \theta \frac{\left(\beta^{j+1}-\beta^{j} \gamma\right)}{\gamma-\beta} C F E_{t-1}\right] \\
& +\left\{\frac{b \theta}{1-\gamma}\left[\frac{1-\beta^{j}}{1-\beta}-\frac{\gamma\left(\gamma^{j}-\beta^{j}\right)}{\gamma-\beta}\right]+b \theta \frac{\gamma\left(\gamma^{j}-\beta^{j}\right)}{\gamma-\beta}\right\}-\left\{\frac{b \theta}{1-\gamma}\left[\frac{1-\beta^{j+1}}{1-\beta}-\frac{\gamma\left(\gamma^{j+1}-\beta^{j+1}\right)}{\gamma-\beta}\right]\right\} \\
& \left.=\beta^{j} \theta b+\gamma \beta^{j} \theta C F E_{t-1}+\beta^{j} u_{t}+\left[\beta v_{t}^{j}+\theta \frac{\gamma\left(\gamma^{j}-\beta^{j}\right)}{\gamma-\beta} v_{t}\right]-\gamma \beta^{j} \theta C F E_{t-1}\right] \\
& +\left\{\frac{b \theta}{1-\gamma}\left[\frac{1-\beta^{j}}{1-\beta}-\frac{\gamma\left(\gamma^{j}-\beta^{j}\right)}{\gamma-\beta}\right]+b \theta \frac{\gamma\left(\gamma^{j}-\beta^{j}\right)}{\gamma-\beta}\right\}-\left\{\frac{b \theta}{1-\gamma}\left[\frac{1-\beta^{j+1}}{1-\beta}-\frac{\gamma\left(\gamma^{j+1}-\beta^{j+1}\right)}{\gamma-\beta}\right]\right\} \\
& =\beta^{j} \theta b+\beta^{j} u_{t}+\left[\frac{\beta^{j} \theta(\gamma-\beta)+\gamma \theta\left(\gamma^{j}-\beta^{j}\right)}{\gamma-\beta} v_{t}\right] \\
& +\left\{\frac{b \theta}{1-\gamma}\left[\frac{1-\beta^{j}}{1-\beta}-\frac{\gamma\left(\gamma^{j}-\beta^{j}\right)}{\gamma-\beta}\right]+b \theta \frac{\gamma\left(\gamma^{j}-\beta^{j}\right)}{\gamma-\beta}\right\}-\left\{\frac{b \theta}{1-\gamma}\left[\frac{1-\beta^{j+1}}{1-\beta}-\frac{\gamma\left(\gamma^{j+1}-\beta^{j+1}\right)}{\gamma-\beta}\right]\right\} \\
& =\beta^{j} \theta b+\beta^{j} u_{t}+\frac{\theta\left(\gamma^{j+1}-\beta^{j+1}\right)}{\gamma-\beta} v_{t}+H
\end{aligned}
$$

where

$$
H=\left\{\frac{b \theta}{1-\gamma}\left[\frac{1-\beta^{j}}{1-\beta}-\frac{\gamma\left(\gamma^{j}-\beta^{j}\right)}{\gamma-\beta}\right]+b \theta \frac{\gamma\left(\gamma^{j}-\beta^{j}\right)}{\gamma-\beta}\right\}-\left\{\frac{b \theta}{1-\gamma}\left[\frac{1-\beta^{j+1}}{1-\beta}-\frac{\gamma\left(\gamma^{j+1}-\beta^{j+1}\right)}{\gamma-\beta}\right]\right\}
$$

Now we turn to simplify $\mathrm{H}$,

$$
\begin{aligned}
& H=\frac{b \theta\left(1-\beta^{j}\right)}{(1-\beta)(1-\gamma)}-\frac{b \theta \gamma\left(\gamma^{j}-\beta^{j}\right)}{(1-\gamma)(\gamma-\beta)}+\frac{\gamma b \theta\left(\gamma^{j}-\beta^{j}\right)(1-\gamma)}{(\gamma-\beta)(1-\gamma)}-\frac{b \theta\left(1-\beta^{j+1}\right)}{(1-\gamma)(1-\beta)}+\frac{b \theta \gamma\left(\gamma^{j+1}-\beta^{j+1}\right)}{(1-\gamma)(\gamma-\beta)} \\
& =\frac{b \theta}{(1-\beta)(1-\gamma)(\gamma-\beta)}\left[\left(1-\beta^{j}\right)(\gamma-\beta)-\gamma^{2}\left(\gamma^{j}-\beta^{j}\right)(1-\beta)-\left(1-\beta^{j+1}\right)(\gamma-\beta)+\gamma\left(\gamma^{j+1}-\beta^{j+1}\right)(1-\beta)\right] \\
& =\frac{b \theta}{(1-\beta)(1-\gamma)(\gamma-\beta)}\left[-\beta^{j}(\gamma-\beta)+\gamma^{2} \beta^{j}(1-\beta)-\beta^{j+1}(1-\gamma) \beta\right] \\
& =\frac{b \theta \beta^{j}}{(1-\beta)(1-\gamma)(\gamma-\beta)}\left[-(\gamma-\beta)+\gamma^{2}(1-\beta)-\beta^{2}(1-\gamma)\right] \\
& =\frac{b \theta \beta^{j}}{(1-\beta)(1-\gamma)(\gamma-\beta)}[-(\gamma-\beta)(1-\beta)(1-\gamma)] \\
& =-b \theta \beta^{j}
\end{aligned}
$$


We thus further simplify (B3),

$$
\begin{aligned}
& \Delta E_{t}\left(A C C E_{t+j}\right)=E_{t}\left(A C C E_{t+j}\right)-E_{t-1}\left(A C C E_{t+j}\right) \\
& =\beta^{j} \theta b+\beta^{j} u_{t}+\frac{\theta\left(\gamma^{j+!}-\beta^{j+1}\right)}{\gamma-\beta} v_{t}+H \\
& =\beta^{j} \theta b+\beta^{j} u_{t}+\frac{\theta\left(\gamma^{j+!}-\beta^{j+1}\right)}{\gamma-\beta} v_{t}+-\beta^{j} \theta b \\
& =\beta^{j} u_{t}+\frac{\theta\left(\gamma^{j+!}-\beta^{j+1}\right)}{\gamma-\beta} v_{t}
\end{aligned}
$$

Summing up the discounted change in the change of expectation of $A C C E_{t+j}$, we obtain:

$$
\begin{aligned}
& \Delta E_{t} \sum_{j=0}^{\infty} \rho^{j} A C C E_{t+j}=\sum_{j=0}^{\infty} \rho^{j}\left[\beta^{j} u_{t}+\frac{\theta\left(\gamma^{j+1}-\beta^{j+1}\right)}{\gamma-\beta} v_{t}\right] \\
& =\sum_{j=0}^{\infty} \rho^{j}\left(\beta^{j} u_{t}+\frac{\theta \gamma}{\gamma-\beta} \gamma^{j} v_{t}-\frac{\theta \beta}{\gamma-\beta} \beta^{j} v_{t}\right) \\
& =\frac{1}{1-\rho \beta} u_{t}+\frac{\theta \gamma}{(\gamma-\beta)(1-\rho \gamma)} v_{t}-\frac{\theta \beta}{(\gamma-\beta)(1-\rho \beta)} v_{t} \\
& =\frac{1}{1-\rho \beta} u_{t}+\frac{\theta}{(1-\rho \gamma)(1-\rho \beta)} v_{t}
\end{aligned}
$$

We now turn to calculate the conditional expectation of $C F E_{t+j}$ at time $t$ :

$$
\begin{aligned}
& E_{t}\left(C F E_{t+j}\right) \\
& =E_{t}\left(b+\gamma C F E_{t+j-1}+v_{t+j}\right) \\
& =b+\gamma E_{t}\left(C F E_{t+j-1}\right)+E_{t}\left(v_{t+j}\right) \\
& =b+\gamma E_{t}\left(b+\gamma C F E_{t+j-2}+v_{t+j-1}\right) \\
& =b(1+\gamma)+\gamma^{2} E_{t}\left(C F E_{t+j-2}\right) \\
& =\ldots \ldots \\
& =b\left(1+\gamma+\gamma^{2}+\ldots+\gamma^{j-1}\right)+\gamma^{j} E_{t}\left(C F E_{t}\right) \\
& =b\left(1-\gamma^{j}\right) /(1-\gamma)+\gamma^{j} C F E_{t}
\end{aligned}
$$

Similarly, we have,

$$
E_{t-1}\left(C F E_{t+j}\right)=b\left(1-\gamma^{j+1}\right) /(1-\gamma)+\gamma^{j+1} C F E_{t-1} .
$$


Given (B4) and (B5), the change of expectation of $C F E_{t+j}$ can be written as,

$\Delta E_{t}\left(C F E_{t+j}\right)=E_{t}\left(C F E_{t+j}\right)-E_{t-1}\left(C F E_{t+j}\right)$

$=\left[b\left(1-\gamma^{j}\right) /(1-\gamma)+\gamma^{j} C F E_{t}\right]-\left[b\left(1-\gamma^{j+1}\right) /(1-\gamma)+\gamma^{j+1} C F E_{t-1}\right]$

$=\gamma^{j}\left(C F E_{t}-b-\gamma C F E_{t-1}\right)$

$=\gamma^{j} v_{t}$

Summing up the discounted change in the change of expectation of $C F E_{t+j}$, we obtain:

$$
\Delta E_{t} \sum_{j=0}^{\infty} \rho^{j} C F E_{t+j}=\frac{1}{1-\rho \gamma} v_{t}
$$

Thus, the discounted change in the change of expectation of $R O E_{t+j}$, according to (B3) and (B6), can be written as,

$$
\begin{aligned}
& \Delta E_{t} \sum_{j=0}^{\infty} \rho^{j} R O E_{t+j}=\Delta E_{t} \sum_{j=0}^{\infty} \rho^{j}\left(A C C E_{t+j}+C F E_{t+j}\right) \\
& =\frac{1}{1-\rho \beta} u_{t}+\frac{\theta}{(1-\rho \gamma)(1-\rho \beta)} v_{t}+\frac{1}{(1-\rho \gamma)} v_{t} \\
& =\frac{1}{1-\rho \beta} u_{t}+\frac{\theta+1-\rho \beta}{(1-\rho \gamma)(1-\rho \beta)} v_{t}
\end{aligned}
$$

Therefore, we have the representation of equation (9),

$$
\operatorname{Var}_{t-1}\left(\Delta E_{t} \sum_{j=0}^{\infty} \rho^{j} R O E_{t+j}\right)=\frac{1}{(1-\rho \beta)^{2}} \operatorname{Var}_{t-1}\left(u_{t}\right)+\frac{(\theta+1-\rho \beta)^{2}}{(1-\rho \beta)^{2}(1-\rho \gamma)^{2}} \operatorname{Var}_{t-1}\left(v_{t}\right) .
$$




\section{REFERENCES}

Abarbanell, J., and V. L. Bernard, 'Tests of Analysts' Overreaction/Underreaction to Earnings Information as an Explanation for Anomalous Stock Price Behavior', Journal of Finance, Vol. 47, No. 3, 1992.

Ang, A., R. J. Hodrick, Y. Xing, and X. Zhang, 'The Cross-Section of Volatility and Expected Returns', Journal of Finance, Vol. 61, No. 1, 2006.

Baginski, S., and J. Wahlen, 'Residual Income Risk, Intrinsic Values, and Share Prices', The Accounting Review, Vol. 78, No. 1, 2003.

Baiman, S., and R. Verrecchia, 'Earnings and Price-Based Compensation Contracts in the Presence of Discretionary Trading and Incomplete Contracting', Journal of Accounting and Economics, Vol. 20, No. 1, 1995.

Ball, R., G. Sadka, and R. Sadka, 'Aggregate Earnings and Asset Prices', Journal of Accounting Research, Vol. 47, No. 5, 2009.

Beaver, W., P. Kettler, and M. Scholes, 'The Association Between Market-Determined and Accounting-Determined Measures of Risk', The Accounting Review, Vol. 45, No. 4, 1970.

Bernard, V., and J. K. Thomas, 'Post-Earnings-Announcement Drift: Delayed Price Response or Risk Premium?', Journal of Accounting Research, Vol. 27, Supplement, 1989.

Bernard, V., and J. K. Thomas, 'Evidence that Stock Prices Do Not Fully Reflect the Implications of Current Earnings for Future Earnings', Journal of Accounting and Economics, Vol. 13, No. 4, 1990.

Brandt, M. W., A. Brav, J. R. Graham, and A. Kumar, 'The Idiosyncratic Volatility Puzzle: Time Trend or Speculative Episodes?', The Review of Financial Studies, Vol. 23, No. 2, 2010.

Brown, L. D., and J. Han, 'Do Stock Prices Fully Reflect the Implications of Current Earnings for Future Earnings for AR1 Firms?', Journal of Accounting Research, Vol. 38, No. 1, 2000.

Bushee, B., and C. Noe, 'Corporate Disclosure Practices, Institutional Investors and Stock Return Volatility', Journal of Accounting Research, Vol. 38, Supplement, 2000.

Callen, J. L., and D. Segal, 'Do Accruals Drive Firm-Level Stock Returns? A Variance Decomposition Analysis', Journal of Accounting Research, Vol. 42, No. 3, 2004.

Campbell, J. Y., M. Lettau, B. G. Malkiel, and Y. Xu, 'Have Individual Stocks Become More Volatile? An Empirical Exploration of Idiosyncratic Risk', Journal of Finance, Vol. 56, No. 1, 2001.

Campbell, J. Y., ‘A Variance Decomposition for Stock Returns', Economic Journal 101, Issue 405, 1991.

Campbell, J. Y., and J. Ammer, What Moves the Stock and Bond Markets? A Variance Decomposition for Long-Term Asset Returns', Journal of Finance, Vol. 48, No. 1, 1993.

Campbell, J. Y., and R. J. Shiller, 'The Dividend-Price Ratio and Expectations of Future Dividends and Discount Factors', Review of Financial Studies, Vol. 1, No. 3, 1998 a.

Campbell, J. Y., and R. J. Shiller, 'Stock Prices, Earnings, and Expected Dividends', Journal of Finance, Vol. 43, No. 3, 1988b.

Chan, L. K. C., J. Lakonishok, and T. Sougiannis, 'The Stock Market Valuation of Research and Development Expenditures', Journal of Finance, Vol. 56, No. 6, 2001.

Chen, L., and X. Zhao, 'Return Decomposition', The Review of Financial Studies Vol. 22, No. 12, 2009. 
Chen, L. H., D. S. Dhaliwal, and M. A. Trombley, 'The Effect of Fundamental Risk on the Market Pricing of Accruals Quality', Journal of Accounting, Auditing and Finance, Vol. 23, No. 2, 2008.

Cheng, Q., 'What Determines Residual Income?', The Accounting Review, Vol. 80, No. 1, 2005.

Cheung, Y., and L. Ng, 'Stock Price Dynamics and Firm Size: An Empirical Investigation', Journal of Finance, Vol. 47, No. 5, 1992.

Christie, W. G., and P. H. Schultz, 'Why Do NASDAQ Market Makers Avoid Odd-Eight Quotes?', Journal of Finance, Vol. 49, No. 4, 1994.

Collins, D. W., M. Pincus, and H. Xie, 'Equity Valuation and Negative Earnings: The Role of Book Value of Equity', The Accounting Review, Vol. 74, No. 1, 1999.

Core, J., W. Guay, and R. Verdi, 'Is Accruals Quality a Priced Risk Factor?', Journal of Accounting and Economics, Vol. 46, No. 1, 2008.

Dechow, P., and I. Dichev, 'The Quality of Accruals and Earnings: The Role of Accrual Estimation Errors, The Accounting Review, Vol. 77, Supplement, 2002.

Duffee, G., 'Stock Returns and Volatility: A Firm-Level Analysis', Journal of Financial Economics, Vol. 37, No. 3, 1995.

Durnev, A., R. Morck, and B. Yeung, 'Value-Enhancing Capital Budgeting and Firm-Specific Stock Return Variation', Journal of Finance, Vol. 59, No. 1, 2004.

Fama, E. F., and K. R. French, 'Common Risk Factors in the Returns on Stocks and Bonds', Journal of Financial Economics, Vol. 33, No. 1, 1993.

Fama, E. F., and K. R. French, 'Multifactor Explanations of Asset Pricing Anomalies', Journal of Finance, Vol. 51, No. 1, 1996.

Fama, E. F., and K. R. French, 'Newly Listed Firms: Fundamentals, Survival Rates, and Returns', Journal of Financial Economics, Vol. 73, No. 2, 2004.

Fama, E. F., and J. D. MacBeth, 'Risk, Return and Equilibrium: Empirical Tests', Journal of Political Economy, Vol. 81, No. 3, 1973.

Feltham, G. A., and J. A. Ohlson, 'Valuation and Clean Surplus Accounting for Operating and Financial Activities', Contemporary Accounting Research, Vol. 11, No. 2, 1995.

Feltham, G. A., and J. A. Ohlson, 'Uncertainty Resolution and the Theory of Depreciation Measurement', Journal of Accounting Research, Vol. 34, No. 2, 1996.

Ferreira, M. A., and P. A. Laux, 'Corporate Governance, Idiosyncratic Risk, and Information Flow', Journal of Finance, Vol. 62, No. 2, 2007.

Francis, J., R. LaFond, P. Olsson, and K. Schipper, 'Costs of Equity and Earnings Attributes', The Accounting Review, Vol, 79, No. 4, 2004.

Francis, J., R. LaFond, P. Olsson, and K. Schipper, K., 'The Market Pricing of Accruals Quality', Journal of Accounting and Economics, Vol. 39, No. 2, 2005.

Francis, J., and K. Schipper, 'Have Financial Statements Lost Their relevance?', Journal of Accounting Research, Vol. 37, No. 2, 1999.

Freeman, R. N., J. A. Ohlson, S. H. and Penman, 'Book-Rate-of-Return and Prediction of Earnings Changes: An Empirical Investigation', Journal of Accounting Research, Vol. 20, No. 2, 1982.

French, K. R., G. W. Schwert, R. F. and Stambaugh, 'Expected Stock Returns and Volatility', Journal of Financial Economics, Vol. 19, No. 1, 1987.

Froot, K. A., A. F. Perold, and J. C. Stein, 'Shareholder Trading Practices and Corporate Investment Horizons', Journal of Applied Corporate Finance, Vol. 5, No. 2, 1992. 
Givoly, D., and C. Hayn, 'The Changing Time-Series Properties of Earnings, Cash Flows and Accruals: Has Financial Reporting Become More Conservative?', Journal of Accounting and Economics, Vol. 29, No. 3, 2000.

Guay, W. R., S. P. Kothari, and R. L. Watts, 'A Market-Based Evaluation of Discretionary Accruals Models', Journal of Accounting Research, Vol. 34, Supplement, 1996.

Guo, H., and X. Jiang, 'Accruals and Conditional Equity Premium', Journal of Accounting Research, Vol. 49, No. 1, 2011.

Hayn, C., 'The Information Content of Losses', Journal of Accounting and Economics, Vol. 20, No. 2, 1995.

Hirshleifer, D., K. Hou, and S. H. Teoh, 'Accruals, Cash Flows, and Aggregate Stock Market Returns', Journal of Financial Economics, Vol. 91, No. 3, 2009.

Hribar, P., and D. W. Collins, 'Errors in Estimating Accruals: Implications for Empirical Research', Journal of Accounting Research, Vol. 40, No. 1, 2002.

Hribar, P., and D. C. Nichols, 'The Use of Unsigned Earnings Quality Measures in Tests of Earnings Management', Journal of Accounting Research, Vol. 45, No. 5, 2007.

Huang, R. D., and H. R. Stoll, 'Dealer Versus Auction Markets: A Paired Comparison of Execution Costs on NASDAQ and the NYSE', Journal of Financial Economics, Vol. 41, No. 3, 1996.

Irvine, P. J., and J. Pontiff, 'Idiosyncratic Return Volatility, Cash Flows, and Product Market Competition', Review of Financial Studies, Vol. 22, No. 3, 2009.

Jones, J. J., 'Earnings Management During Import Relief Investigations', Journal of Accounting Research, Vol. 29, No. 2, 1991.

Kang, Q., Q. Liu, and R. Qi, 'Predicting Stock Market Returns with Aggregate Discretionary Accruals', Journal of Accounting Research, Vol. 48, No. 4, 2010.

Kim, D., and Y. Qi, 'Accruals Quality, Stock Returns, and Macroeconomic Conditions', The Accounting Review, Vol. 85, No. 3, 2010.

Liu, M., and P. Wysocki, 'Cross-Sectional Determinants of Information Quality Proxies and Cost of Capital Measures', Working paper, MIT, 2007.

Malkiel, B. G., and Y. Xu, 'Investigating the Behavior of Idiosyncratic Volatility', Journal of Business, Vol. 76, No. 4, 2003.

Mashruwala, C. A., and S. D. Mashruwala, 'The Pricing of Accruals Quality: January Versus the Rest of the Year', The Accounting Review, Vol. 86, No. 4, 2011.

Nekrasov, A., and P. K. Shroff, 'Fundamentals-Based Risk Measurement in Valuation', The Accounting Review, Vol. 84, No. 6, 2009.

Newey, W. K., and K. D. West, 'A Simple, Positive Semi-Definite, Heteroskedasticity and Autocorrelation Consistent Covariance Matrix’, Econometrica,Vol. 55, No. 3, 1987.

Ogneva, M., 'Accrual Quality, Realized Returns, and Expected Returns: The Importance of Controlling for Cash Flow Shocks', Working paper, Stanford University, 2010.

Ohlson, J. A., 'Earnings, Book Values, and Dividends in Equity Valuation', Contemporary Accounting Research, Vol. 11, No. 2, 1995.

Pástor, L., and P. Veronesi, 'Stock Valuation and Learning about Profitability', Journal of Finance, Vol. 58, No. 5, 2003.

Pástor, L., and P. Veronesi, 'Was There a NASDAQ Bubble in the Late 1990's?', Journal of Financial Economics, Vol. 81, No. 1, 2006.

Penman, S., Financial Statement Analysis and Security Valuation, McGraw-Hill Irwin, 2006. 
Petersen, M. A., 'Estimating Standard Errors in Finance Panel Data Sets: Comparing Approaches', Review of Financial Studies, Vol. 22, No. 1, 2009.

Schwert, G. W., 'Why Does Stock Market Volatility Change Over Time?', Journal of Finance, Vol. 44, No. $5,1989$.

Schwert, G. W., 'Stock Volatility in the New Millennium: How Wacky is Nasdaq?', Journal of Monetary Economics, Vol. 49, No. 1, 2002.

Shleifer, A., and R. W. Vishny, 'The Limits of Arbitrage', Journal of Finance, Vol. 52, No. 1, 1997.

Subramanyam, K. R., 'The Pricing of Discretionary Accruals', Journal of Accounting and Economics, Vol. 22, No. 1-3, 1996.

Vuolteenaho, T., 'What Drives Firm-Level Stock Returns?', Journal of Finance, Vol. 57, No. 1, 2002.

Wei, S. X., and C. Zhang, 'Why Did Individual Stocks Become More Volatile?', Journal of Business, Vol. 79, No. 1, 2006.

Wysocki, P. D., 'Assessing Earnings and Accruals Quality: U.S. and International Evidence', Working paper, MIT Sloan School of Management, 2009.

Yee, K. K., 'Earnings Quality and the Equity Risk Premium: A Benchmark Model', Contemporary Accounting Research, Vol. 23, No. 3, 2006. 


\section{Measurement}

\section{Panel A: Stock Return Volatility*}

Total Volatility (TVOL)

Idiosyncratic volatility from CAPM

(IVOLC)

Idiosyncratic volatility from

Fama-French model (IVOLF)

Systematic volatility (SVOLC)

Systematic volatility (SVOLF)
The sample variance of daily stock returns over the year

The sum of squared residuals from the CAPM model divided by the number of trading days within the year

The sum of squared residuals from the Fama-French three factor model divided by the number of trading days within the year

Total volatility minus idiosyncratic volatility from CAPM

Total volatility minus idiosyncratic volatility from Fama-French model

* All volatility measures are multiplied by 10000 , and calculated from the fourth month after the fiscal year-end, with the assumption that financial statement numbers is publicly available within three months after the fiscal year-end.

\section{Panel B: Firm-specific control variables}

ROE

Firm stock return (RETURN)

AGE

SIZE

Leverage (LEV)

Book-to-market ratio (BM)
Net income before extraordinary items / lagged total shareholder's equity

Annual buy-and-hold returns, calculated from the fourth month after the fiscal year-end

The logarithm of the number of years from the tracking date of the firm appearing in the COMPUSTAT to the current year

The logarithm of the firm's market value of equity at the end of fiscal year, market value of equity is defined as Common shares outstanding times Price - fiscal year - close

(Total Long-term debt + Debt in current liabilities / Total assets

Book value of equity / market value of equity

\section{Panel C: Accounting accrual variables}

Accruals (ACC)

Accrual variability (VAC_1)
The growth rate of net operating assets (i.e. $\left.\mathrm{NOA}_{\mathrm{t}} / \mathrm{NOA}_{\mathrm{t}-1}-1\right)$. Net operating asset $(\mathrm{NOA})=$ operating assets minus operating liabilities (See Feltham and Ohlson 1996; Callen and Segal 2004)

The sample variance of yearly ACC observations over the past five 
Total accruals (ACCE)

Cash flow components of earnings (CFE)

Total accrual variability (VAC_2)

FundVAC_1

DiscVAC_1

FundVAC_2

DiscVAC_2 years for a minimum of 5 observations

Total accruals / lagged total shareholder's equity. Total accruals are defined as change in current assets - change in current liabilities change in cash and cash equivalents + change in debt in current liabilities - depreciation and amortization expense. (See Francis et al. 2005; Callen and Segal 2004)

\section{ROE minus ACCE}

The sample variance of yearly ACCE observations over the past five years for a minimum of 5 observations

The fundamental component of VAC_1 paralleling the decomposition approach of Francis et al. (2005)

The discretionary component of VAC_1 paralleling the decomposition approach of Francis et al. (2005)

The fundamental component of VAC_2 paralleling the decomposition approach of Francis et al. (2005)

The discretionary component of VAC_2 paralleling the decomposition approach of Francis et al. (2005)

\section{Panel D: Determinants of fundamental accrual variability}

Total asset (TA)

Cash flow variability (VCFE)

Revenues variability (VREV)

Length of operating (OperCycle)

Incidence of negative earnings realizations (NegEarn)
The natural logarithm of total assets

The sample variance of the firm's rolling five-year cash flows from operations, scaled by lagged book value of equity

The sample variance of the firm's rolling five-year sales revenues, scaled by lagged book value of equity

cycle The natural logarithm of the sum of days accounts receivable and day inventory, that is, OperCycle $=360 /($ Sales $/$ Average accounts receivable $)+360 /($ Cost of Goods Sold $) /($ Average Inventory)

The number of firm-years with negative earnings divided by the total number of firm-years for each firm over past five years 


\section{TABLE 2}

\section{DESCRIPTIVE STATISTICS OF KEY VARIABLES}

This table presents the summary statistics of five measures of stock return volatility, key variables, determinants of fundamental accrual variability and other control variables. The definition of all variables can be found in Table 1 .

\begin{tabular}{|c|c|c|c|c|c|}
\hline \multirow[b]{2}{*}{ Stock Return Volatility } & \multirow[t]{2}{*}{ Mean } & \multirow[t]{2}{*}{ Median } & \multirow[t]{2}{*}{ Stdev } & \multirow[t]{2}{*}{ Skew } & \multirow[t]{2}{*}{ Kurt } \\
\hline & & & & & \\
\hline TVOL & 14.600 & 6.429 & 22.752 & 3.565 & 18.690 \\
\hline IVOL from CAPM & 13.870 & 5.756 & 22.407 & 3.628 & 19.195 \\
\hline IVOL from FF model & 13.532 & 5.544 & 22.038 & 3.644 & 19.312 \\
\hline SVOL from CAPM & 0.633 & 0.260 & 0.978 & 2.993 & 14.036 \\
\hline SVOL from FF model & 0.966 & 0.473 & 1.354 & 2.956 & 13.945 \\
\hline LOG(TVOL) & 1.955 & 1.861 & 1.168 & 0.343 & 2.613 \\
\hline LOG(IVOL from CAPM) & 1.857 & 1.750 & 1.204 & 0.360 & 2.584 \\
\hline LOG(IVOL from FF model) & 1.824 & 1.713 & 1.209 & 0.366 & 2.588 \\
\hline LOG(SVOL from CAPM) & -1.701 & -1.346 & 2.007 & -0.947 & 3.925 \\
\hline LOG(SVOL from FF model) & -0.857 & -0.749 & 1.408 & -0.359 & 2.822 \\
\hline \multicolumn{6}{|l|}{ Accrual variables } \\
\hline ROE & 0.045 & 0.106 & 0.266 & -1.925 & 8.101 \\
\hline ACCE & -0.091 & -0.079 & 0.235 & -0.399 & 7.540 \\
\hline CFE & 0.120 & 0.160 & 0.346 & -1.155 & 8.417 \\
\hline $\mathrm{ACC}$ & 0.130 & 0.062 & 0.458 & 3.630 & 26.366 \\
\hline VAC_1 & 0.302 & 0.059 & 0.955 & 5.270 & 35.045 \\
\hline VAC_2 & 0.120 & 0.012 & 0.514 & 8.910 & 98.774 \\
\hline LOG(VAC_1) & -1.352 & -2.801 & 2.443 & 0.697 & 3.018 \\
\hline LOG(VAC_2) & -4.296 & -4.381 & 1.789 & 0.352 & 2.917 \\
\hline FundVAC_1 & -2.312 & -2.381 & 1.084 & 0.261 & 2.651 \\
\hline DiscVAC_1 & 0.000 & -0.113 & 1.818 & 0.920 & 3.968 \\
\hline FundVAC_2 & -4.249 & -4.322 & 1.511 & 0.347 & 2.940 \\
\hline DiscVAC_2 & 0.000 & 0.049 & 0.794 & -0.610 & 3.844 \\
\hline \multicolumn{6}{|l|}{ Control Variables } \\
\hline Return & 1.142 & 1.084 & 0.489 & 1.198 & 6.000 \\
\hline Size & 4.892 & 4.812 & 2.075 & 0.159 & 2.477 \\
\hline $\log ($ Age (months) $)$ & 4.667 & 4.691 & 1.001 & -0.090 & 2.254 \\
\hline Lev & 0.238 & 0.216 & 0.187 & 0.556 & 2.523 \\
\hline $\mathrm{BM}$ & 0.842 & 0.671 & 0.651 & 1.830 & 7.393 \\
\hline \multicolumn{6}{|l|}{$\begin{array}{l}\text { Determinants of Fundamental Accrual } \\
\text { Variability }\end{array}$} \\
\hline $\log ($ Total Asset (Millions)) & 5.462 & 5.359 & 2.155 & 0.179 & 2.407 \\
\hline LOG(Cash flow variability) & -3.968 & -4.070 & 2.054 & 0.368 & 3.353 \\
\hline LOG(Revenues variability) & -5.168 & -4.728 & 2.657 & -0.661 & 3.488 \\
\hline Length of operating cycle & 5.106 & 4.914 & 1.074 & 1.330 & 4.748 \\
\hline Incidence of negative earnings realizations & 0.209 & 0.000 & 0.321 & 1.398 & 3.647 \\
\hline
\end{tabular}


TABLE 3

\section{ESTIMATION OF FUNDAMENTAL AND DisCRETIONARY ACCRUAL UnCERTAINTY}

The approach parallels those in Francis et al. (2005) to the fundamental accrual uncertainty as a function of known economic determinants, including firm size, cash flow variability, sales variability, length of operating cycle, and incidence of negative earnings realizations. Firm size is proxied by the $\log$ of total assets $(T A)$. Cash flow variability, $\log (V C F E)$, is measured as the $\log$ of the sample variance of the firm's rolling five-year cash flows from operations, scaled by book values of equity. Sales variability, $\log (V R E V)$, is the $\log$ of the sample variance of the firm's rolling five-year sales revenues, scaled by total assets. Operating cycle, (OperCycle), is the log of the sum of the firm's days accounts receivable and days inventory. Incidence of negative earnings realizations, (NegEarn), is calculated as the firm's proportion of losses over the prior five years. The discretionary component is measured as the residual from regressing accruals variability on fundamental factors. We run the following cross-sectional regression to identify the two components of accrual uncertainty:

$$
\log \left(\text { Accrual_Variability }_{i}\right)=c_{0}+\sum_{j=1}^{n} c_{j} * \text { fundamental }_{j, i}+\varepsilon_{i}
$$

where, for each firm $i, \log$ (Accrual_Variability) is the $\log$ of accruals variability, fundamental ${ }_{j, i}$ is the $j$ 'th fundamental factor, $j=1,2, \ldots, n$, where $n$ is the number of fundamental factors. A separate regression of equation (12) is estimated for each fiscal year, with each regression using all available observations of that year. The residual from equation (12) is the estimate of the discretionary component of firm $i$ 's accrual uncertainty, and the predicted values are the estimate of the fundamental component. The mean coefficient estimates from the annual regression of equation (12), and the reported $t$-statistics in parentheses are based on the time-series standard errors.

\begin{tabular}{lccccc}
\hline & \multicolumn{3}{c}{ LOG(VAC_1) } & LOG(VAC_2) \\
\cline { 2 - 6 } & Expected sign & Coefficient & t-value & Coefficient & t-value \\
\hline Constant & & $-1.526^{* * *}$ & $(-5.50)$ & $-1.747^{* * * *}$ & $(-19.27)$ \\
LOG(Total assets (Millions)) & - & $-0.068^{* * *}$ & $(-2.93)$ & $-0.038^{* * * *}$ & $(-6.82)$ \\
LOG(Cash flow variability) & + & $0.311^{* * *}$ & $(15.96)$ & $0.762^{* * *}$ & $(55.17)$ \\
LOG(Revenues variability) & + & $0.328^{* * *}$ & $(17.97)$ & $0.148^{* * *}$ & $(15.36)$ \\
Length of operating cycle & + & $0.398^{* * *}$ & $(8.93)$ & $0.298^{* * *}$ & $(15.99)$ \\
Incidence of negative earnings & + & $1.253^{* * *}$ & $(6.87)$ & $0.491^{* * *}$ & $(5.43)$ \\
& + & & & & \\
Adj. $\mathrm{R}^{2}$ & & 0.214 & & 0.698 & \\
\hline
\end{tabular}


TABLE 4

\section{REgRESSIONS OF STOCK RETURN VOLATILITY ON ACCRUAL VARIABILITY AND OTHER VARIABLES}

This table represents results from the regression of stock return volatility on accrual variability and control variables at the firm level.

$$
\log \left(\operatorname{VOL}_{i, t}\right)=\beta_{0}+\beta \log \left(\text { Accrual_Variability }_{i, t-1}\right)+\sum_{j=1}^{n} \gamma_{j} * \operatorname{control}_{j, i}+\varepsilon_{i, t}
$$

$V O L_{t}$ is a proxy for total volatility, idiosyncratic volatility or systematic volatility respectively in year $t$. Accrual_Variability is the accrual variability representing VAC_1 or VAC_2 in year $t-1$, control $_{i}$ is the $j$ 'th control variable, $j=1,2, \ldots, n$, where $n$ is the number of control variables, including $R O E$ Return-on-equity in year $t$-1, RETURN the contemporaneous annual buy-and-hold returns in year $t$, $S I Z E$ the natural logarithm of the firm's market value of equity in year $t-1, A G E$ the logarithm of the number of years from the tracking date of the firm appearing in the CRSP to year $t-1, L E V$ the sum of long-term debt and current liabilities over the book value of total assets in year $t-1$, and $B M$ the ratio of the book value of equity to the market value of equity in year $t-1$. All variables of interest have been standardized to facilitate interpretation of the results. Figures in parentheses are robust $t$-statistics using standard errors corrected for both clustering by firm and clustering by year. *** (**,*) indicates significant at the $1 \%(5 \%, 10 \%)$ level for two tailed test.

\begin{tabular}{|c|c|c|c|c|}
\hline \multirow[t]{2}{*}{ Variables } & \multicolumn{2}{|c|}{ Panel A: VAC_1 } & \multicolumn{2}{|c|}{ Panel B: VAC_2 } \\
\hline & $(1)$ & $(2)$ & (3) & (4) \\
\hline Constant & $\begin{array}{l}0.024 \\
(0.37)\end{array}$ & $\begin{array}{l}0.026 \\
(0.42)\end{array}$ & $\begin{array}{l}0.086 \\
(1.18)\end{array}$ & $\begin{array}{c}0.111^{*} \\
(1.68)\end{array}$ \\
\hline VAC_1 & $\begin{array}{c}0.303 * * * \\
(13.48)\end{array}$ & $\begin{array}{c}0.144 * * * \\
(5.79)\end{array}$ & & \\
\hline VAC_2 & & & $\begin{array}{c}0.347 * * * \\
(22.28)\end{array}$ & $\begin{array}{c}0.192 * * * \\
(13.97)\end{array}$ \\
\hline Roe & & $\begin{array}{c}-0.304 * * * \\
(-15.39)\end{array}$ & & $\begin{array}{c}-0.292 * * * \\
(-12.71)\end{array}$ \\
\hline Return & & $\begin{array}{c}-0.074 * \\
(-1.93)\end{array}$ & & $\begin{array}{c}-0.068 * * \\
(-1.98)\end{array}$ \\
\hline Size & & $\begin{array}{c}-0.379 * * * \\
(-11.03)\end{array}$ & & $\begin{array}{c}-0.288 * * * \\
(-7.67)\end{array}$ \\
\hline Age & & $\begin{array}{c}-0.136 * * * \\
(-4.97)\end{array}$ & & $\begin{array}{c}-0.223 * * * \\
(-8.18)\end{array}$ \\
\hline Lev & & $\begin{array}{l}-0.005 \\
(-0.39)\end{array}$ & & $\begin{array}{c}-0.077 * * * \\
(-7.27)\end{array}$ \\
\hline $\mathrm{BM}$ & & $\begin{array}{c}-0.120 * * * \\
(-5.00)\end{array}$ & & $\begin{array}{c}-0.074 * * * \\
(-3.34)\end{array}$ \\
\hline Adj. $\mathrm{R}^{2}$ & 0.053 & 0.349 & 0.116 & 0.413 \\
\hline
\end{tabular}




\section{TABLE 5}

\section{REGRESSIONS OF STOCK RETURN VOLATILITY ON THE FUNDAMENTAL AND Discretionary COMPONENTS OF ACCRUAL VARIABILITY AND OTHER VARIABLES}

This table represents results from the regression of stock return volatility on the fundamental and discretionary components of accrual variability and control variables at the firm level.

$$
\log \left(\operatorname{VOL}_{i, t}\right)=\beta_{0}+\beta_{1} \log \left(\text { FundVAC }_{i, t-1}\right)+\beta_{2} \log \left(\operatorname{DiscVAC}_{i,-l}\right)+\sum_{j=1}^{n} \gamma_{j} * \operatorname{control}_{j, i}+\varepsilon_{i, t}
$$

$V O L_{t}$ is a proxy for total volatility, idiosyncratic volatility or systematic volatility respectively in year $t$. FundVAC and DiscVAC are the fundamental and discretionary components of accrual variability in year $t-1$, control $_{i}$ is the $j$ 'th control variable, $j=1,2, \ldots, n$, where $n$ is the number of control variables, including ROE Return-on-equity in year $t-1, R E T U R N$ the contemporaneous annual buy-and-hold returns in year $t$, SIZE the natural logarithm of the firm's market value of equity in year $t-1, A G E$ the logarithm of the number of years from the tracking date of the firm appearing in the CRSP to year $t-1$, $L E V$ the sum of long-term debt and current liabilities over the book value of total assets in year $t-1$, and $B M$ the ratio of the book value of equity to the market value of equity in year $t-1$. All variables of interest have been standardized to facilitate interpretation of the results. Figures in parentheses are robust $t$-statistics using standard errors corrected for both clustering by firm and clustering by year. *** $(* *, *)$ indicates significant at the $1 \%(5 \%, 10 \%)$ level for two tailed test.

\begin{tabular}{|c|c|c|c|c|c|c|c|c|}
\hline \multirow[b]{2}{*}{ Variables } & \multicolumn{4}{|c|}{ Panel A: VAC_1 } & \multicolumn{4}{|c|}{ Panel B: VAC_2 } \\
\hline & (1) & (2) & (3) & (4) & (5) & (6) & (7) & (8) \\
\hline Constant & $\begin{array}{l}0.041 \\
(0.82)\end{array}$ & $\begin{array}{l}0.018 \\
(0.27)\end{array}$ & $\begin{array}{l}0.039 \\
(0.78)\end{array}$ & $\begin{array}{c}0.137 * * \\
(2.23)\end{array}$ & $\begin{array}{l}-0.089 \\
(-1.49)\end{array}$ & $\begin{array}{l}-0.087 \\
(-1.35)\end{array}$ & $\begin{array}{l}-0.097 \\
(-1.64)\end{array}$ & $\begin{array}{l}0.085 \\
(1.22)\end{array}$ \\
\hline FundVAC_1 & $\begin{array}{c}0.524 * * * \\
(24.03)\end{array}$ & & $\begin{array}{c}0.524 * * * \\
(24.23)\end{array}$ & $\begin{array}{c}0.339 * * * \\
(15.43)\end{array}$ & & & & \\
\hline DiscVAC_1 & & $\begin{array}{c}0.069 * * * \\
(5.19)\end{array}$ & $\begin{array}{c}0.034 * * * \\
(3.33)\end{array}$ & $\begin{array}{c}0.033 * * * \\
(3.97)\end{array}$ & & & & \\
\hline FundVAC_2 & & & & & $\begin{array}{c}0.416 * * * \\
(28.46)\end{array}$ & & $\begin{array}{c}0.419 * * * \\
(28.66)\end{array}$ & $\begin{array}{c}0.250 * * * \\
(19.95)\end{array}$ \\
\hline DiscVAC_2 & & & & & & $\begin{array}{l}0.005 \\
(0.56)\end{array}$ & $\begin{array}{l}0.005 \\
(0.55)\end{array}$ & $\begin{array}{l}0.001 \\
(0.07)\end{array}$ \\
\hline Roe & & & & $\begin{array}{c}-0.218 * * * \\
(-10.46)\end{array}$ & & & & $\begin{array}{c}-0.309 * * * * \\
(-14.56)\end{array}$ \\
\hline Return & & & & $\begin{array}{c}-0.048^{*} \\
(-1.69)\end{array}$ & & & & $\begin{array}{l}-0.049 \\
(-1.49)\end{array}$ \\
\hline Size & & & & $\begin{array}{c}-0.235^{* * * *} \\
(-6.07)\end{array}$ & & & & $\begin{array}{c}-0.257 * * * \\
(-7.17)\end{array}$ \\
\hline Age & & & & $\begin{array}{c}-0.173 * * * \\
(-5.03)\end{array}$ & & & & $\begin{array}{c}-0.206^{* * * *} \\
(-5.57)\end{array}$ \\
\hline Lev & & & & $\begin{array}{l}-0.003 \\
(-0.19)\end{array}$ & & & & $\begin{array}{c}-0.063 * * * \\
(-4.91)\end{array}$ \\
\hline $\mathrm{BM}$ & & & & $\begin{array}{l}-0.024 \\
(-1.30)\end{array}$ & & & & $\begin{array}{c}-0.061 * * * \\
(-2.94)\end{array}$ \\
\hline Adj. $R^{2}$ & 0.299 & 0.005 & 0.301 & 0.431 & 0.192 & 0.000 & 0.193 & 0.386 \\
\hline
\end{tabular}




\section{TABLE 6}

\section{REgReSSIONS OF SYSTEMATIC STOCK RETURN Volatility ON ACCRUAL VARIABILITY AND OTHER VARIABLES}

This table represents results from the regression of stock return volatility on accrual variability and control variables at the firm level.

$$
\begin{gathered}
\log \left(\operatorname{VOL}_{i, t}\right)=\beta_{0}+\beta \log \left(\text { Accrual_Variability }_{i, t-1}\right)+\sum_{j=1}^{n} \gamma_{j} * \operatorname{control}_{j, i}+\varepsilon_{i, t} \\
\log \left(\operatorname{VOL}_{i, t}\right)=\beta_{0}+\beta_{1} \log \left(\text { FundVAC }_{i, t-1}\right)+\beta_{2} \log \left(\operatorname{DiscVAC}_{i, t-1}\right)+\sum_{j=1}^{n} \gamma_{j} * \operatorname{control}_{j, i}+\varepsilon_{i, t}
\end{gathered}
$$

$V O L_{t}$ is a proxy for total volatility, idiosyncratic volatility or systematic volatility respectively in year $t$. Accrual_Variability is the accrual variability representing VAC_1 or VAC_2 in year $t, F u n d V A C$ and DiscVA $\bar{C}$ are the fundamental and discretionary components of accrual variability in year $t-1$, control $_{i}$ is the $j$ 'th control variable, $j=1,2, \ldots, n$, where $n$ is the number of control variables, including $R O E$ Return-on-equity in year $t-1, R E T U R N$ the contemporaneous annual buy-and-hold returns in year $t$, $S I Z E$ the natural logarithm of the firm's market value of equity in year $t-1, A G E$ the logarithm of the number of years from the tracking date of the firm appearing in the CRSP to year $t-1, L E V$ the sum of long-term debt and current liabilities over the book value of total assets in year $t-1$, and $B M$ the ratio of the book value of equity to the market value of equity in year $t-1$. All variables of interest have been standardized to facilitate interpretation of the results. Figures in parentheses are robust $t$-statistics using standard errors corrected for both clustering by firm and clustering by year. *** (**,*) indicates

\begin{tabular}{|c|c|c|c|c|c|c|c|c|}
\hline \multirow[b]{2}{*}{ Variables } & \multicolumn{4}{|c|}{ Panel A: VAC_1 } & \multicolumn{4}{|c|}{ Panel B: VAC_2 } \\
\hline & (1) & (2) & (3) & (4) & (5) & (6) & (7) & (8) \\
\hline \multirow[t]{2}{*}{ Constant } & -0.014 & -0.026 & 0.049 & $0.107^{*}$ & 0.062 & 0.075 & 0.001 & 0.069 \\
\hline & $(-0.23)$ & $(-0.45)$ & $(0.81)$ & $(1.80)$ & $(0.86)$ & (1.19) & $(0.01)$ & (1.14) \\
\hline \multirow[t]{2}{*}{ VAC_1 } & $0.144 * * *$ & $0.106 * * *$ & & & & & & \\
\hline & $(8.92)$ & (7.66) & & & & & & \\
\hline \multirow[t]{2}{*}{ FundVAC_1 } & & & $0.186 * * *$ & $0.244 * * *$ & & & & \\
\hline & & & (7.79) & $(8.88)$ & & & & \\
\hline \multirow[t]{2}{*}{ DiscVAC_1 } & & & $0.070 * * *$ & $0.040 * * *$ & & & & \\
\hline & & & $(5.65)$ & (3.63) & & & & \\
\hline \multirow[t]{2}{*}{ VAC_2 } & & & & & $0.132 * * *$ & $0.118 * * *$ & & \\
\hline & & & & & $(9.31)$ & $(11.15)$ & & \\
\hline \multirow[t]{2}{*}{ FundVAC_2 } & & & & & & & $0.170 * * *$ & $0.230 * * *$ \\
\hline & & & & & & & $(10.65)$ & $(14.35)$ \\
\hline \multirow[t]{2}{*}{ DiscVAC_2 } & & & & & & & 0.012 & 0.009 \\
\hline & & & & & & & (1.43) & $(0.97)$ \\
\hline \multirow[t]{2}{*}{ Roe } & & $-0.200 * * *$ & & $-0.100 * * *$ & & $-0.184 * * *$ & & $-0.160 * * *$ \\
\hline & & $(-8.68)$ & & $(-4.07)$ & & $(-8.61)$ & & $(-5.44)$ \\
\hline \multirow[t]{2}{*}{ Return } & & -0.002 & & 0.021 & & 0.009 & & 0.019 \\
\hline & & $(-0.05)$ & & $(0.58)$ & & $(0.25)$ & & $(0.50)$ \\
\hline \multirow[t]{2}{*}{ Size } & & $0.208 * * *$ & & $0.287 * * *$ & & $0.258 * * *$ & & $0.291 * * *$ \\
\hline & & $(5.87)$ & & $(8.27)$ & & (7.87) & & $(9.16)$ \\
\hline \multirow[t]{2}{*}{ Age } & & $-0.058 * *$ & & $-0.123 * * *$ & & $-0.145 * * *$ & & $-0.132 * * *$ \\
\hline & & $(-2.20)$ & & $(-4.08)$ & & $(-5.61)$ & & $(-4.14)$ \\
\hline Lev & & 0.009 & & 0.011 & & $-0.067 * * *$ & & $-0.045^{* *}$ \\
\hline
\end{tabular}
significant at the $1 \%(5 \%, 10 \%)$ level for two tailed test. 


$\begin{array}{ccccc} & (0.58) & (0.50) & (-4.05) & (-2.48) \\ \mathrm{BM} & -0.072^{* * *} & 0.028 & -0.036^{*} & 0.005 \\ & (-3.62) & (1.28) & (-1.79) & (0.22)\end{array}$

Adj. $\mathrm{R}^{2}$

0.020

0.089

0.044

0.110

0.018

0.112

0.032

0.105 


\section{TABLE 7}

\section{REGRESSIONS OF IDIOSYNCRATIC STOCK RETURN VOLATILITY ON ACCRUAL VARIABILITY AND OTHER VARIABLES}

This table represents results from the regression of stock return volatility on accrual variability and control variables at the firm level.

$$
\begin{gathered}
\log \left(\operatorname{VOL}_{i, t}\right)=\beta_{0}+\beta \log \left(\text { Accrual_Variability }_{i, t-1}\right)+\sum_{j=1}^{n} \gamma_{j} * \operatorname{control}_{j, i}+\varepsilon_{i, t} \\
\log \left(\operatorname{VOL}_{i, t}\right)=\beta_{0}+\beta_{1} \log \left(\text { FundVAC }_{i, t-1}\right)+\beta_{2} \log \left(\text { DiscVAC }_{i, t-1}\right)+\sum_{j=1}^{n} \gamma_{j} * \operatorname{control}_{j, i}+\varepsilon_{i, t}
\end{gathered}
$$

$V O L_{t}$ is a proxy for total volatility, idiosyncratic volatility or systematic volatility respectively in year $t$. Accrual_Variability is the accrual variability representing VAC_1 or VAC_2 in year $t, F u n d V A C$ and DiscVAC are the fundamental and discretionary components of accrual variability in year $t-1$, control $_{i}$ is the $j$ 'th control variable, $j=1,2, \ldots, n$, where $n$ is the number of control variables, including $R O E$ Return-on-equity in year $t-1, R E T U R N$ the contemporaneous annual buy-and-hold returns in year $t$, SIZE the natural logarithm of the firm's market value of equity in year $t-1, A G E$ the logarithm of the number of years from the tracking date of the firm appearing in the CRSP to year $t-1, L E V$ the sum of long-term debt and current liabilities over the book value of total assets in year $t-1$, and $B M$ the ratio of the book value of equity to the market value of equity in year $t-1$. All variables of interest have been standardized to facilitate interpretation of the results. Figures in parentheses are robust $t$-statistics using standard errors corrected for both clustering by firm and clustering by year. *** (**, *) indicates

\begin{tabular}{|c|c|c|c|c|c|c|c|c|}
\hline \multirow[b]{2}{*}{ Variables } & \multicolumn{4}{|c|}{ Panel A: VAC_1 } & \multicolumn{4}{|c|}{ Panel B: VAC_2 } \\
\hline & (1) & (2) & (3) & (4) & (5) & (6) & (7) & (8) \\
\hline \multirow[t]{2}{*}{ Constant } & 0.024 & 0.033 & 0.035 & $0.137 * *$ & 0.085 & $0.116^{*}$ & $-0.103^{*}$ & 0.085 \\
\hline & $(0.36)$ & $(0.52)$ & $(0.71)$ & $(2.15)$ & (1.18) & $(1.72)$ & $(-1.82)$ & $(1.22)$ \\
\hline \multirow[t]{2}{*}{ VAC_1 } & $0.329 * * *$ & $0.162 * * *$ & & & & & & \\
\hline & $(13.85)$ & (5.96) & & & & & & \\
\hline \multirow[t]{2}{*}{ FundVAC_1 } & & & $0.532 * * *$ & $0.327 * * *$ & & & & \\
\hline & & & $(26.33)$ & $(15.30)$ & & & & \\
\hline \multirow[t]{2}{*}{ DiscVAC_1 } & & & $0.026 * * *$ & $0.029 * * *$ & & & & \\
\hline & & & $(2.62)$ & $(3.71)$ & & & & \\
\hline \multirow[t]{2}{*}{ VAC_2 } & & & & & $0.353 * * *$ & $0.178 * * *$ & & \\
\hline & & & & & $(22.47)$ & $(14.29)$ & & \\
\hline \multirow[t]{2}{*}{ FundVAC_2 } & & & & & & & $0.426 * * *$ & $0.237 * * *$ \\
\hline & & & & & & & $(31.10)$ & $(20.98)$ \\
\hline \multirow[t]{2}{*}{ DiscVAC_2 } & & & & & & & 0.007 & 0.001 \\
\hline & & & & & & & $(0.83)$ & $(0.05)$ \\
\hline \multirow[t]{2}{*}{ Roe } & & $-0.297 * * *$ & & $-0.217 * * *$ & & $-0.282 * * *$ & & $-0.306 * * *$ \\
\hline & & $(-14.42)$ & & $(-9.89)$ & & $(-11.62)$ & & $(-13.81)$ \\
\hline \multirow[t]{2}{*}{ Return } & & $-0.076^{* *}$ & & $-0.051 *$ & & $-0.070 * *$ & & $-0.051 *$ \\
\hline & & $(-2.12)$ & & $(-1.94)$ & & $(-2.15)$ & & $(-1.68)$ \\
\hline \multirow[t]{2}{*}{ Size } & & $-0.430 * * *$ & & $-0.289 * * *$ & & $-0.342 * * *$ & & $-0.315 * * *$ \\
\hline & & $(-13.22)$ & & $(-7.66)$ & & $(-9.49)$ & & $(-9.37)$ \\
\hline \multirow[t]{2}{*}{ Age } & & $-0.153 * * *$ & & $-0.177 * * *$ & & $-0.236^{* * *}$ & & $-0.210 * * *$ \\
\hline & & $(-5.81)$ & & $(-5.21)$ & & $(-9.11)$ & & $(-5.84)$ \\
\hline
\end{tabular}
significant at the $1 \%(5 \%, 10 \%)$ level for two tailed test. 


$\begin{array}{ccccc}\text { Lev } & -0.008 & -0.001 & -0.070 * * * & -0.057 * * * \\ & (-0.67) & (-0.06) & (-7.27) & (-4.71) \\ \text { BM } & -0.124 * * * & -0.030 & -0.077 * * * & -0.065 * * * \\ & (-4.59) & (-1.61) & (-2.93) & (-3.10)\end{array}$

Adj. $\mathrm{R}^{2}$

0.050

0.393

0.306

0.469

0.117

0.454

0.198

0.431 


\section{TABLE 8}

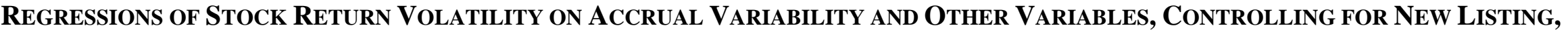

\section{TECHNOLOGY AND LOSS FIRMS}

This table represents results from the regression of total stock return volatility on accrual variability and control variables at the firm level.

$$
\begin{aligned}
& \log \left(\operatorname{VOL}_{i, t}\right)=\beta_{0}+\beta \log \left(\text { Accrual_Variability }_{i, t-1}\right)+\sum_{j=1}^{n} \gamma_{j} * \operatorname{control}_{j, i}+\varepsilon_{i, t} \\
& \log \left(\operatorname{VOL}_{i, t}\right)=\beta_{0}+\beta_{1} \log \left(\text { FundVAC }_{i, t-1}\right)+\beta_{2} \log \left(\operatorname{DiscVAC}_{i, t-1}\right)+\sum_{j=1}^{n} \gamma_{j} * \operatorname{control}_{j, i}+\varepsilon_{i, t}
\end{aligned}
$$

$V O L_{t}$ is a proxy for total volatility, idiosyncratic volatility or systematic volatility respectively in year $t$. Accrual_Variability is the accrual variability representing VAC_1 or VAC_ 2 in year $t, F u n d V A C$ and DiscVAC are the fundamental and discretionary components of accrual variability in year $t-1$, control $_{i}$ is the $j$ 'th control variable, $j=1,2, \ldots, n$, where $n$ is the number of control variables, including ROE Return-on-equity in year $t-1, R E T U R N$ the contemporaneous annual buy-and-hold returns in year $t$, SIZE the natural logarithm of the firm's market value of equity in year $t-1, A G E$ the logarithm of the number of years from the tracking date of the firm appearing in the CRSP to year $t-1, L E V$ the sum of long-term debt and current liabilities over the book value of total assets in year $t$-1, and $B M$ the ratio of the book value of equity to the market value of equity in year $t$ - 1 . All variables of interest have been standardized to facilitate interpretation of the results. Figures in parentheses are robust $t$-statistics using standard errors

\begin{tabular}{|c|c|c|c|c|c|c|c|c|c|c|}
\hline \multirow[b]{2}{*}{ Variables } & \multicolumn{2}{|c|}{ Panel A: New firms } & \multicolumn{2}{|c|}{ Panel B: Old firms } & \multicolumn{2}{|c|}{ Panel C: Loss firms } & \multicolumn{2}{|c|}{$\underline{\text { Panel D: Profit firms }}$} & \multicolumn{2}{|c|}{$\frac{\text { Panel E: Non-Technology }}{\underline{\text { firms }}}$} \\
\hline & (1) & (2) & (3) & (4) & (5) & (6) & (7) & (8) & (9) & (10) \\
\hline Constant & $\begin{array}{c}0.378 * * * \\
(6.15)\end{array}$ & $\begin{array}{c}0.398 * * * \\
(6.20)\end{array}$ & $\begin{array}{c}-0.155^{* * *} \\
(-4.07)\end{array}$ & $\begin{array}{c}-0.245^{* * * *} \\
(-5.93)\end{array}$ & $\begin{array}{c}0.230 * * * \\
(3.43)\end{array}$ & $\begin{array}{c}0.302 * * * \\
(3.70)\end{array}$ & $\begin{array}{l}0.123^{*} \\
(1.95)\end{array}$ & $\begin{array}{l}0.056 \\
(0.81)\end{array}$ & $\begin{array}{l}0.093 \\
(1.56)\end{array}$ & $\begin{array}{l}0.025 \\
(0.37)\end{array}$ \\
\hline FundVAC_1 & $\begin{array}{c}0.231 * * * \\
(18.02)\end{array}$ & & $\begin{array}{c}0.302 * * * \\
(11.35)\end{array}$ & & $\begin{array}{c}0.246^{* * *} \\
(8.71)\end{array}$ & & $\begin{array}{c}0.351 * * * \\
(15.68)\end{array}$ & & $\begin{array}{c}0.331 * * * \\
(15.15)\end{array}$ & \\
\hline DiscVAC_1 & $\begin{array}{c}0.052 * * * \\
(5.46)\end{array}$ & & $\begin{array}{c}0.029 * * \\
(2.17)\end{array}$ & & $\begin{array}{c}0.028 * * \\
(2.39)\end{array}$ & & $\begin{array}{c}0.033 * * * \\
(3.63)\end{array}$ & & $\begin{array}{c}0.029 * * * \\
(3.00)\end{array}$ & \\
\hline FundVAC_2 & & $\begin{array}{c}0.159 * * * \\
(12.06)\end{array}$ & & $\begin{array}{c}0.258 * * * \\
(20.51)\end{array}$ & & $\begin{array}{c}0.156^{* * *} \\
(7.19)\end{array}$ & & $\begin{array}{c}0.270 * * * \\
(20.65)\end{array}$ & & $\begin{array}{c}0.247 * * * \\
(18.97)\end{array}$ \\
\hline
\end{tabular}
corrected for both clustering by firm and clustering by year. *** $(* * *)$ indicates significant at the $1 \%(5 \%, 10 \%)$ level for two tailed test. 


\begin{tabular}{|c|c|c|c|c|c|c|c|c|c|c|}
\hline \multirow[t]{2}{*}{ DiscVAC_2 } & & 0.003 & & 0.005 & & $0.039 * * *$ & & 0.008 & & 0.006 \\
\hline & & ) & & ..78) & & (3.67) & & $(0.84)$ & & $(0.87)$ \\
\hline Roe & $\begin{array}{c}-0.137 * * * \\
(-9.52)\end{array}$ & $\begin{array}{c}-0.191 * * * \\
(-11.78)\end{array}$ & $\begin{array}{c}-0.212^{* * *} \\
(-11.62)\end{array}$ & $\begin{array}{c}-0.260^{* * * *} \\
(-12.46)\end{array}$ & $\begin{array}{c}-0.205^{* * *} \\
(-9.60)\end{array}$ & $\begin{array}{c}-0.288 * * * \\
(-12.16)\end{array}$ & $\begin{array}{c}-0.213^{* * * *} \\
(-7.88)\end{array}$ & $\begin{array}{c}-0.297 * * * \\
(-9.76)\end{array}$ & $\begin{array}{c}-0.241^{* * * *} \\
(-12.36)\end{array}$ & $\begin{array}{c}-0.318^{* * *} \\
(-16.60)\end{array}$ \\
\hline Return & $\begin{array}{c}-0.089^{* * *} \\
(-3.14)\end{array}$ & $\begin{array}{c}-0.090 \text { **** } \\
(-3.04)\end{array}$ & $\begin{array}{l}-0.003 \\
(-0.12)\end{array}$ & $\begin{array}{l}-0.012 \\
(-0.40)\end{array}$ & $\begin{array}{c}-0.075^{* * *} \\
(-2.94)\end{array}$ & $\begin{array}{c}-0.083^{* * *} \\
(-2.89)\end{array}$ & $\begin{array}{l}-0.036 \\
(-1.16)\end{array}$ & $\begin{array}{l}-0.035 \\
(-1.03)\end{array}$ & $\begin{array}{l}-0.042 \\
(-1.53)\end{array}$ & $\begin{array}{l}-0.046 \\
(-1.43)\end{array}$ \\
\hline Size & $\begin{array}{c}-0.407 * * * \\
(-10.29)\end{array}$ & $\begin{array}{c}-0.439^{* * * *} \\
(-11.31)\end{array}$ & $\begin{array}{c}-0.255^{* * *} \\
(-8.45)\end{array}$ & $\begin{array}{c}-0.268^{* * * *} \\
(-9.85)\end{array}$ & $\begin{array}{c}-0.320^{* * * *} \\
(-6.91)\end{array}$ & $\begin{array}{c}-0.334 * * * \\
(-7.47)\end{array}$ & $\begin{array}{c}-0.210^{* * * *} \\
(-5.54)\end{array}$ & $\begin{array}{c}-0.232 * * * \\
(-6.74)\end{array}$ & $\begin{array}{c}-0.231^{* * * *} \\
(-6.09)\end{array}$ & $\begin{array}{c}-0.255^{* * *} \\
(-7.07)\end{array}$ \\
\hline Age & $\begin{array}{l}-0.051 \\
(-1.09)\end{array}$ & $\begin{array}{l}-0.016 \\
(-0.31)\end{array}$ & $\begin{array}{l}0.016 \\
(0.59)\end{array}$ & $\begin{array}{l}0.016 \\
(0.59)\end{array}$ & $\begin{array}{c}-0.158^{* * * *} \\
(-3.97)\end{array}$ & $\begin{array}{c}-0.203^{* * *} \\
(-5.04)\end{array}$ & $\begin{array}{c}-0.176^{* * * *} \\
(-5.08)\end{array}$ & $\begin{array}{c}-0.203 * * * \\
(-5.54)\end{array}$ & $\begin{array}{c}-0.164 * * * \\
(-4.82)\end{array}$ & $\begin{array}{c}-0.186 * * * \\
(-5.20)\end{array}$ \\
\hline Lev & $\begin{array}{l}-0.020 \\
(-1.51)\end{array}$ & $\begin{array}{c}-0.074 * * * \\
(-5.36)\end{array}$ & $\begin{array}{c}0.048^{* *} \\
(2.18)\end{array}$ & $\begin{array}{l}-0.009 \\
(-0.53)\end{array}$ & $\begin{array}{l}-0.028 \\
(-1.64)\end{array}$ & $\begin{array}{c}-0.063 * * * \\
(-4.02)\end{array}$ & $\begin{array}{l}-0.000 \\
(-0.01)\end{array}$ & $\begin{array}{c}-0.059 * * * \\
(-4.21)\end{array}$ & $\begin{array}{l}0.019 \\
(1.17)\end{array}$ & $\begin{array}{c}-0.036 * * * \\
(-2.66)\end{array}$ \\
\hline $\mathrm{BM}$ & $\begin{array}{c}0.026^{*} \\
(1.87)\end{array}$ & $\begin{array}{l}0.014 \\
(0.99)\end{array}$ & $\begin{array}{l}-0.025 \\
(-1.58)\end{array}$ & $\begin{array}{c}-0.053^{* * * *} \\
(-3.29)\end{array}$ & $\begin{array}{l}-0.040 \\
(-1.42)\end{array}$ & $\begin{array}{c}-0.070 * * \\
(-2.40)\end{array}$ & $\begin{array}{l}-0.019 \\
(-1.06)\end{array}$ & $\begin{array}{c}-0.057 * * * \\
(-2.88)\end{array}$ & $\begin{array}{l}-0.013 \\
(-0.69)\end{array}$ & $\begin{array}{c}-0.042 * * \\
(-2.05)\end{array}$ \\
\hline Adj. $R^{2}$ & 0.485 & 0.451 & 0.333 & 0.313 & 0.363 & 0.326 & 0.361 & 0.322 & 0.410 & 0.366 \\
\hline
\end{tabular}


${ }^{1}$ Most existing studies hypothesize that firm managers respond to economic events by adjusting accruals in a particular direction for a specific economic motive, and thus naturally concentrate on the level of accounting accruals.

${ }^{2}$ Theoretically, accounting accruals can be thought of as an observed signal (s) characterized as a firm's fundamental value (v) plus a noise term that reflects managerial discretions and errors (e), that is, $\mathrm{s}=\mathrm{v}+\mathrm{e}$. The variability of the accrual signal can therefore be decomposed into two components: var ( $\mathrm{s}$ ) $=\operatorname{var}(\mathrm{v})+\operatorname{var}(\mathrm{e})$, where $\operatorname{var}(\mathrm{v})$ is a firm's underlying fundamental volatility and $\operatorname{var}(\mathrm{e})$ reflects the discretionary uncertainty.

3 Callen and Segal (2004) adopt the Feltham-Ohlson clean surplus relations but do not use the information dynamics as proposed in Feltham and Ohlson $(1995,1996)$.

4 Although both the Callen-Segal model and the Vuolteenaho model incorporate the clean surplus relation, Callen and Segal (2004) use the clean surplus relation in the fashion of Feltham and Ohlson $(1995,1996)$. More importantly, the Vuolteenaho model emphasises earnings news as measured by net income, while the focus of the Callen-Segal model is on accruals in the Feltham-Ohlson framework.

5 Reasons why volatility is important include the relation between perceived riskiness and cost of capital (Froot et al. 1992); high stock return volatility can make stock-price-based compensation less effective and more costly (Baiman and Verrecchia 1995); evidence that investment strategies based on volatility can earn statistically and economically significant abnormal returns (e.g. Ang et al. 2006); and finally, the price of an option on an individual stock depends on the volatility of its return, and accordingly, arbitrageurs who trade to exploit the mispricing of an individual stock face risks related to firm-level volatility in the sense that larger pricing error may be associated with higher return volatility (Shleifer and Vishny 1997).

6 While some studies of volatility determinants adopt a variance decomposition approach, such an approach is not consistent with our theoretical predictions. More importantly, Ball et al. (2009) and Chen and Zhao (2009) show that the variance decomposition approach has several serious limitations. For example, the expected-return news in the variance decomposition approach cannot be accurately measured due to low predictive power, and the cash flow news, when treated as the residual, inherits the large misspecification error of the expected-return news. A missing state variable in the variance decomposition approach is likely to alter the empirical conclusion. In contrast, such model misspecification is much less damaging for regression analysis. Even if a factor is missing in a regression model, we can still draw statistical inferences about the specified factors despite increased noise, provided the omitted variable is not highly correlated with the specified factors. In addition, inverting the procedure in the variance decomposition approach, by first modelling expected cash flows and then backing out expected returns, could reverse the results and lead to the opposite conclusion.

7 Hirshleifer et al. (2009) document that aggregate accruals positively predict aggregate stock returns and innovations in aggregate accruals are negatively correlated with contemporaneous market returns, suggesting accruals news contains information about discount rate news, or that firms manage earnings 
in response to market wide undervaluation. In favour of the earnings management explanation, Kang et al. (2010) find that the results in Hirshleifer et al. (2009) are driven by discretionary accruals. On the other hand, Guo and Jiang (2011) present evidence consistent with the risk-based explanation and suggest that aggregate accruals, as a proxy for the conditional equity premium, forecast changes in aggregate economic activity.

8 Mashruwala and Mashruwala (2011) find that high AQ stocks outperform low AQ stocks only in January rather than the rest of the year, which is inconsistent with a risk interpretation of accrual quality.

9 Our use of accrual variability also avoids the common criticisms directed at the use of the Jones (1991) approach for decomposing accruals into expected and unexpected (discretionary) components. Methodological difficulties include potential omitted variables such as operating choices that have non-earnings management rationales but affect discretionary accruals, misstated discretionary accruals models and the problem of lack-of-power.

10 Consistent with Yee (2006)'s predictions, Chen et al. (2008) provide empirical evidence that the pricing effect of accrual quality on the cost of capital increases with fundamental risk.

11 Liu and Wysocki (2007) also argue that the documented relation between accrual quality and cost of capital is primary driven by the volatility of firms' operating activities, which are less subject to managerial manipulation.

12 Following Francis et al. (2004), for our robustness checks we require at least ten observations for estimating the residuals from equations (3) or (8).

13 A large part of the accounting literature suggest that the market is naive in recognizing the time-series properties of earnings encapsulated in public financial accounting information, and hence causes significant post-earnings-announcement abnormal returns (e.g., Bernard and Thomas 1989, 1990). However, recent studies seek to refine the understanding of the drift. Brown and Han (2000) suggest the market is not entirely naive, but underestimates the parameters of the true process. In particular, Abarbanell and Bernard (1992) conclude that the market's failure to accurately process the time-series properties of earnings is due in part to dependence on analysts' forecast errors.

14 Liu and Wysocki (2007) argue that operating volatility, such as cash flow volatility, captures underlying constructs that differ from accrual quality. While accrual quality is (in theory) solely related to the manager's accounting choices, operating volatility tends to capture a firm's operating decisions that are (1) not related to accounting, (2) likely to occur continuously throughout the fiscal year, and (3) less subject to managerial manipulation.

15 To avoid survivorship bias in the sample selection, we ensure that all active and inactive firms on the three stock exchanges are included in the sample, so that the population of firms within each exchange and each year represents, as near as possible, the 'true' population of firms that existed over the sample period. 
16 All volatility measures are multiplied by 10,000. Inferences are unchanged when the definition of volatility adopted by French et al. (1987) is used.

17 Usually annual financial statement numbers are not reported to stock markets at the end of the fiscal year. It is assumed that the accounting information is publicly available within three months after the fiscal year-end. We therefore calculate all volatility measures and annual buy-and-hold stock returns from the fourth month after the fiscal year-end.

18 For robustness, the final sample is also truncated by winsorizing extreme observations of key variables at the top and bottom one percentile of their distributions each year. The results are qualitatively similar.

19 The main results continue to hold if using sales revenues rather than total assets.

20 For brevity, correlations are not presented here, but are available upon request. 